\section{Corrosion Properties of a Low- Nickel Austenitic Porous Stainless Steel in Simulated Body Fluids}

\author{
C. Garcia-Cabezon, * F. Martin-Pedrosa, ,**** Y. \\ Blanco-Val* and M.L. Rodriguez-Mendez**
}

\section{Universidad de Valladolid, Spain}

\section{Keywords:}

Stainless steel

Microstructure

X-ray diffraction

Anodic polarization

Electrochemical impedance spectroscopy (EIS)

*Materials Engineering, E.I.I., Universidad de Valladolid. C/ Paseo del Cauce 59, 47011 Valladolid, Spain.

**Department of Inorganic Chemistry, E.I.I., Universidad de Valladolid, C/ Paseo del Cauce 59, 47011 Valladolid, Spain. ***Corresponding author: tel.: +34 983423515; fax: +34 983184514.
Email: fmp@eii.uva.es.

\begin{abstract}
Nickel can cause severe allergic reactions. Therefore, efforts are made to reduce the content of nickel in austenitic stainless steels. Powder metallurgy techniques can produce this steel in a highly affordable way. A novel low-nickel high-nitrogen austenitic powder metallurgy stainless steel is investigated in terms of corrosion behavior. Nitrogen, because of its gammagenic effect, is the applied sintering atmosphere. Two sintering processes are applied by controlling the sinter-cooling rate (furnace- and water-cooling). This material shows a free of precicipitates austenitic microstructure only after the water-cooling process. The electrochemical behavior in two simulated body fluids, phosphate buffered saline solution (PBS) and Ringer solution, are studied. Corrosion behavior is evaluated by means of anodic polarization measurements and cyclic polarization curves. In addition, Electrochemical Impedance Spectroscopy is used to evaluate the corrosion resistance of this steel in PBS at open circuit potential and at $100 \mathrm{mV}$ above corrosion potential. The water-cooling process promotes better corrosion behavior in simulated body fluids for high nitrogen and low nickel than a conventional (high nickel) austenitic powder metallurgy stainless steel 316LN type.
\end{abstract}

\section{INTRODUCTION}

Biomaterials are an important research area that has expanded rapidly over the last few decades. Metallic biomaterials, such as stainless steels (SS), Co-Cr-Mo alloys, or titanium and its alloys, are used in several medical devices and implants. ${ }^{1}$ Austenitic SS are widely used as biomaterials because of their low cost as compared to other metallic biomaterials, their good mechanical and corrosion resistant properties, their easy processing and their adequate biocompatibility. The austenitic matrix in these materials is mainly obtained thanks to the high content of nickel, which is also a major contributor to the cost and price volatility of austenitic SS. ${ }^{2}$ Furthermore, when nickel bearing SS are used for biomedical purposes, the presence of chloride ions in the human body generates corrosion processes. Nickel ions from these corrosion products can cause severe allergic reactions such as swelling, reddening eczema and itching. ${ }^{3}$ Because of this, there is a long history of searching for alternatives to nickel in SS, dating from $1950 .^{4}$ Therefore, in recent years, low nickel and nickel free austenitic SS have attracted much attention, ${ }^{5,6}$ especially focusing on biomedical applications. $^{7,8}$

Furthermore, from a metallurgical point of view, nickel plays an important role in the formation and stabilization of austenite and in the corrosion resistance of passive film. ${ }^{9}$ However, other elements, such as nitrogen, manganese, carbon and copper, are also austeniteforming elements. A recent study on low-nickel austenitic SS concluded that nitrogen is the main alloying element that can replace some or all of the nickel. ${ }^{5}$ This nitrogen, if it is in solid solution, is a strong austenite stabilizer, which enhances hardness, strength and corrosion resistance, and reveals a large potential for strain hardening. ${ }^{10}$ Unfortunately, there is also a drawback to this because, when nitrogen content is high, precipitation of chromium nitride/carbonitride particles can occur and, consequently, the toughness and corrosion resistance fall drastically. ${ }^{6,7}$ Nonetheless, it has been shown that highnitrogen nickel-free SS is a promising coronary stent material with excellent mechanical properties, sufficient corrosion resistance and satisfactory biocompatibility. It also has especially outstanding hemocompatibility. ${ }^{11}$ The effect of nitrogen has been studied by some authors. Menzel et al. developed a nickel-free $\mathrm{Cr}-\mathrm{Mn}$-Mo austenite SS with up to $1 \% \mathrm{~N}$, which exhibited a good combination of strength, toughness and corrosion resistance with a good cost-efficiency. ${ }^{6}$ Sumita et al. ${ }^{7}$ concluded that the addition of nitrogen improves the strength, ductility, wear and corrosion resistance of nickel-free steel for metallic biomaterials. Some manufacturing methods, such as the nitrogenization of surfaces in nitrogen gas at $1200^{\circ} \mathrm{C}$, have been developed to machine these biomaterials. ${ }^{7}$ The beneficial effect of nitrogen on the behavior of biocorrosion has been explained as a result of the thicker and more protective passive film formation. ${ }^{12}$ The passive films of high-nitrogen SS behave as n-type semiconductors and the donor density decreases by nitrogen addition, thus indicating more benefits for hemocompatibility. ${ }^{11}$ Finally, it has been proven that nitrogen protects and improves the electronic properties of the passive oxide layer in austenitic SS in acid solution. ${ }^{13}$

High-pressure melting techniques ${ }^{14}$ are currently used to obtain conventional high-nitrogen SS, which require expensive equipment. On the contrary, powder metallurgy (PM) techniques are becoming promising methods to produce these steels in a highly affordable way. ${ }^{15}$ The PM processing generally consists of three steps: powder mixing, die compaction, and sintering. Compaction is typically performed at room temperature, while sintering is conducted at high temperature under a carefully controlled atmosphere. It is at this high temperature where the powders are joined together thanks to the diffusion of their elemental components. The PM processes provide a feasible and economical manufacturing of austenitic SS components with complex shape. Advantages such as good dimensional precision, high surface finish and adequate mechanical properties are obtained. The inherent porosity of PM materials is not necessarily a drawback for the field of implantology, ${ }^{16,17}$ but it is true that the mechanical properties and corrosion resistance of PM stainless steels is lower than that of either cast or wrought stainless steels. ${ }^{18-20}$ The influence of sintering parameters on density behavior ${ }^{21}$ and mechanical 
properties ${ }^{22,23}$ has been studied. In recent years, metallic porous materials have attracted much interest as candidates for biomedical applications because the gradual porosity is used as an essential parameter in implantology. ${ }^{16}$ The mismatch of elastic moduli of the implant and surrounding bone can be minimized by introducing pores in SS parts, thereby improving the fixation and enhancing the bone ingrowth and osseointegration. Metallic foams of AISI 316L SS (UNS S31603) were made for porous biomedical applications, ${ }^{17}$ although massive steel had a better corrosion performance than the foams, as the porosity contributes to increasing the area exposed to the corrosion medium. The control of the compaction pressure and the sintering atmosphere allows austenitic SS to be obtained with the functional properties required for successful implantations in the human body. ${ }^{24}$

It is not an easy task to obtain low or nickel-free SS powders. Salahinejad et al. ${ }^{25,26}$ and Suryananarayan ${ }^{27}$ have developed porous nanocrystalline high-manganese nickel-free austenitic SS by mechanical alloy with manganese and nitrogen. The milling time under a nitrogen atmosphere was the most important parameter; when this time increases, the densification is retarded. However, the hardness and compressive yield strength are enhanced. Another manufacturing method, spark plasma sintering, was applied to nitrogen-containing, high-manganese, and nickel-free SS powders. ${ }^{21}$ The effect of the size of the powders and the sintering temperature on the mechanical properties was investigated. $^{21}$

Corrosion of metal implants is critical because it can adversely affect biocompatibility and mechanical integrity. There are many studies on the characterization and enhancement of the corrosion resistance of conventional austenitic stainless steel for medical applications. Kocijan et al. studied the corrosion behavior of $316 \mathrm{~L}$ under both open circuit potentials and potentiostatic conditions, ${ }^{28}$ also using potentiodynamic measurement in artificial saliva. ${ }^{29}$ The corrosion behavior of $316 \mathrm{~L}$ and other metallic materials was investigated by Karimi et al., ${ }^{30}$ using open circuit potential (OCP), potentiostatic and potentiodynamic experiments in phosphate buffered saline (PBS). Burstein and Liu reported on pitting corrosion with $316 \mathrm{~L}$ in Ringer solution. ${ }^{31}$ Shahryari et al. ${ }^{32,33}$ demonstrated the enhancement of the corrosion resistance of a biomedical grade 316 SS by electrochemical cyclic voltammetry. The film formed on the surface is a very efficient passivation method to improve the general and pitting corrosion resistances.

Höganäs has recently developed a novel low-nickel high-nitrogen austenitic powder metallurgy SS. ${ }^{34}$. In this case, the austenitic microstructure is obtained exclusively by nitrogen addition. There is no $\mathrm{Mn}$, which in turn gives some advantages. Manganese dramatically reduces material compressibility. Therefore, some special compaction and sintering processes, such as hot isostatic pressing, should be used. Furthermore, $\mathrm{Mn}$ in powder form shows a very high reactivity with oxygen, especially at high temperatures, so extremely clean sintering atmospheres are required. Consequently, the absence of $\mathrm{Mn}$ is quite desirable. In a previous work of the authors, ${ }^{35}$ a microstructural study was performed and the acid corrosion behavior was evaluated in terms of anodic polarization measurements and an electrochemical potentiokinetic reactivation test in acid chloride $\left(1 \mathrm{~N} \mathrm{H}_{2} \mathrm{SO}_{4}+0.5 \mathrm{M}\right.$ $\mathrm{NaCl}$ ). It was found that a fast sinter-cooling process (water quenching) was advisable for good acid corrosion resistance. On the contrary, the ordinary sinter-cooling process (slow cooling) revealed an undesirable microstructure and corrosion behavior. Finally, the hardening effect of nitrogen was also observed. This effect was the highest for the watercooled sample, where all the nitrogen is dissolved in the austenite phase. The scope of this work is to extend the knowledge of this novel material by studying its biocorrosion behavior. As nitrogen shows a strong gammagenic effect, the sintering atmosphere was of this gas.
However, nitrogen can promote nitride/carbonitride formation during sinter-cooling. ${ }^{18,35}$ Nonetheless, a solution has been found to this for PM 316L, ${ }^{19,36-38}$ in that a rapid cooling from sintering temperature can avoid the formation of those precipitates. This work investigates the effect of two sinter-cooling rates, a slow and a fast cooling from sintering temperature. To analyze the corrosion behavior, anodic polarization measurements, cyclic polarization curves and electrochemical impedance spectroscopy (EIS) were used. Two typical electrolytes, PBS and Ringer solutions, ${ }^{30,31}$ were used as inorganic solutions to simulate the corrosiveness of the body fluids.

\section{EXPERIMENTAL PROCEDURES}

\section{Materials}

A novel water atomized powder is used in this work (herein designated as HNSS). ${ }^{34}$ The powder composition is designed to enable the production of low-nickel, low-manganese sintered SS components. Since this material is intended to be a low cost SS, the content of Mo was as low as 0.5 wt $\%$. A second material, used herein on a comparative basis, is a commercial water atomized powder 316LHD (UNS S31603), also from the same company (herein referred to as $316 \mathrm{LN})$. The chemical composition of the materials after sintering is shown in Table 1. The nickel content of HNSS was reduced by at least $60 \%$ with respect to $316 \mathrm{LN}$.

Disc specimens ( $12 \mathrm{~mm}$ in diameter and $6 \mathrm{~mm}$ in height) were uniaxially compacted at $750 \mathrm{MPa}$ for $300 \mathrm{~s}$ using a floating die and zinc stearate as die lubricant. Density of the samples were measured at this stage (green density). Sintering at $1250{ }^{\circ} \mathrm{C}$ in $\mathrm{N}_{2}-\mathrm{H}_{2}$ (95\% - $5 \%$ ) for 60 min was selected. After this heating time, two different sinter-cooling processes were introduced. Some samples were cooled in the furnace at a slow rate of $5{ }^{\circ} \mathrm{C} / \mathrm{min}$ (referred to from now on as the "furnacecooling" process). Some others were subjected to fast cooling by direct immersion in water from the sintering oven (designated from now on as the "water-cooling" process). Again density was measured after sintering the samples (sintering density).

After sintering, a porosity study was done by image analysis; the measured parameters were degree of porosity, number of pores, sphericity, and pore area. Density was also determined by the Archimedes method. ${ }^{35}$

Samples were polished and etched before observation by optical metallography and scanning electron microscopy with energy dispersive analysis of X-rays (SEM/EDS). A SEM-FEI (QUANTA 200F) was used to record the images of the electrode surfaces. A EDAX Genesis Apex System was used for EDS measurements. Oxalic acid electrolytic etch and Vilella's reagent were used depending on the feature of interest. X-ray diffraction (XRD) Bruker Discover D8 was used to assist in the identification of some of the phases. A set of five samples were obtained for each sinter-cooling process. The microstructural and porosity studies confirmed that differences between samples of the same set were small. To assure repeatability, the electrochemical tests were repeated three times, either on the same sample or on different ones.

\section{Anodic Polarization Measurements}

The potentiodynamic anodic polarization curves were obtained by following ASTM standard G-5. ${ }^{39}$ A EG\&G Model 273A Potentiostat / Galvanostat was used. Surface preparation of the samples was performed with $1 \mu \mathrm{m}$ diamond paste polishing. Nitrogen streaming and agitation were used throughout the whole test. The experiments were carried out using two different simulated body fluids: a PBS solution $\left(8.0 \mathrm{~g} / \mathrm{l} \mathrm{NaCl}, 0.2 \mathrm{~g} / \mathrm{l} \mathrm{KCl}, 0.594 \mathrm{~g} / \mathrm{l} \mathrm{Na}{ }_{2} \mathrm{HPO}_{4}, 0.2 \mathrm{~g} / \mathrm{I} \mathrm{KH}_{2} \mathrm{PO}_{4}\right)$ and $\mathrm{a}$ 
Ringer solution $\left(8.6 \mathrm{~g} / \mathrm{l} \mathrm{NaCl}, 0.3 \mathrm{~g} / \mathrm{l} \mathrm{KCl}, 0.264 \mathrm{~g} / \mathrm{I} \mathrm{CaCl}_{2}\right)$. The temperature of the solutions was kept out $37^{\circ} \mathrm{C}$ and $\mathrm{pH} 7.44$ for PBS and 7.35 for Ringer solution (human body conditions). A Saturated Calomel Electrode (SCE) was used as reference electrode. The experimental test procedure was as follows: First, a 5 min delay at open circuit (OC) potential followed by a step at $-220 \mathrm{mV}_{\mathrm{SCE}}$ during 2 min for anodic attack; then a delay of $2 \mathrm{~min}$ at $\mathrm{V}_{\mathrm{OC}}$, a 1 min cathodic cleaning at $-600 \mathrm{mV}_{\mathrm{SCE}}$, a 5 min delay at OC potential, and finally an anodic potentiodynamic scan, which started at $200 \mathrm{mV}_{\mathrm{SCE}}$ below $\mathrm{V}_{\mathrm{OC}}$, reaching $1000 \mathrm{mV}_{\text {SCE }}$. Two potential scan rates were set at 50 and 10 $\mathrm{mV} / \mathrm{min}$ (herein designated as fast and slow scan rate, respectively). Polarization was performed at least three times under each condition.

\section{Cyclic Polarization Curves}

The cyclic potentiodynamic polarization curves were obtained according to ASTM standard G-61 except for the limiting current that was fixed to $0.1 \mathrm{~A}$ instead of $5 \mathrm{~mA}$. $^{40}$ The specimens were polished up to $1 \mu \mathrm{m}$ diamond finish. The polarization curves were recorded in a PBS solution at a temperature of $37^{\circ} \mathrm{C} \pm 1$. This electrolyte was chosen based on the results of the anodic polarization measurements. Before polarization, the samples were immersed in the test solution for 1 hour at $\mathrm{V}_{\mathrm{OC}}$. The electrode potential was scanned from $\mathrm{V}_{\mathrm{OC}}$ at a $50 \mathrm{mV} / \mathrm{min}$ sweep rate. When the current reached $0.1 \mathrm{~A}$, the scanning direction was reversed until $V_{O C}$ in order to evaluate the repassivation tendency. Polarization was performed at least three times.

\section{Electrochemical Impedance Spectroscopy}

EIS was used to estimate the electrochemical parameters associated with the corrosion process occurring on the four samples during immersion in the PBS solution. A Solartron 1260A Impedance/Gainphase analyzer was used in these experiments. A three-electrode corrosion cell and deareated with nitrogen was used for the EIS measurements. The test specimen used as a working electrode was exposed to the solution with an area of $1.13 \mathrm{~cm}^{2}$. Two graphite bars and SCE electrode were used as the counter-electrode and reference electrode, respectively. The impedance measurements were carried out from a $40 \mathrm{kHz}$ down to $0.01 \mathrm{~Hz}$ frequency range with 10 steps per decade and using $10 \mathrm{mV}$ peak-to-peak sinusoidal perturbation. The test specimens were allowed to stabilize in PBS solution under OCP condition for 30 minutes prior to the electrochemical tests. After this, one full set of samples was measured at OCP. Each experiment was repeated three times to ensure their repeatability. Finally, the impedance data were analyzed with Zview software (Scribner Associates, Inc.) and initially fitted to different equivalent electrical circuits.

\section{RESULTS AND DISCUSSION}

\section{Microstructural Study}

Small changes in porosity were observed for the two sinter-cooling rates and the two materials, ${ }^{35}$ Table 2 . Therefore, it is expected that porosity is influencing the four samples in the same way. Porosity reduction during sintering is a slow process based on diffusion, so it is reasonable to expect similar values of porosity. Furthermore, the furnace-cooled samples showed the lowest sintering density and the highest values of porosity, though differences were not very significant. This could be explained by: first, considering the fact that nitrogen slows down the sintering process and causes the loss of relative density; ${ }^{22}$ and second, that $\mathrm{Cr}_{2} \mathrm{~N}$ is present for furnace-cooled samples, thus reducing the diffusion rate, which results in a lower sinter density. ${ }^{24}$

The microstructure was found to be clearly dependent on the cooling process. ${ }^{35}$ Accordingly, the mechanical and corrosion properties also changed. The microstructure of furnace-cooled HNSS revealed two constituents $^{35}$ (Figures $1[\mathrm{a}]$ and $1[\mathrm{~b}]$ ). Austenite grains in a large proportion and a 'lamellar constituent' formed by lamellae of chromium precipitates in chromium depleted matrix. ${ }^{35}$ The cell morphology of the lamellar constituent has been described elsewhere ${ }^{18,19}$ and is typical of the discontinuous mechanism of precipitation. Furthermore, an intense intergranular (IG) and slight transgranular (TG) precipitation was found. This microstructure is similar to that of furnace-cooled $316 \mathrm{LN},{ }^{18}$ although the latter showed more and larger cells of lamellar constituent. The lamellar constituent was a direct consequence of the slow sinter-cooling process. On the other hand, for water-cooled HNSS, a more homogeneous material was obtained; no precipitation of chromium nitride/carbonitride was observed. A single phase with twined grains was identified as the austenite phase (Figure 1[c]). SEM micrographs for water-cooled $316 \mathrm{LN}$ and HNSS confirmed this fact (Figure 2). The composition of the austenite grains for these two samples was obtained by EDS, Table 3. As expected the chemical composition was different, but was, in both cases, identified as austenite. However, the austenite grains are not identical. In effect, some small magnetic response was detected in all the samples except the water-cooled HNSS. For the furnace-cooled samples such magnetism was expected because of the lamellar constituent. However, this should not be the case for the water-cooled samples, where it was supposed the only phase present was austenite. This could be satisfactorily explained by the fact that it is possible to detect some $\alpha^{\prime}$-martensite in water-cooled 316LN by XRD (Figure 3 ). This martensite has been identified in some other cases ${ }^{20}$ and is defined as a strain induced martensite caused by the dissolution of $\mathrm{N}$ in austenite, which promotes the expansion of the austenite. It is the origin of internal stresses that cause plastic deformation. Moreover, no martensite was found in the water-cooled HNSS, which suggests a more stable austenite, as demonstrated in a previous work. ${ }^{35}$

It can be concluded that, especially for HNSS, the water-cooling process provides an austenitic microstructure free of precipitates. The slow cooling process promotes the presence of a lamellar constituent plus IG and TG precipitates. Of course, an alternative way to obtain an austenitic microstructure would be an annealed solution of the furnace-cooled samples, but water-cooling is preferred since time and energy consumption are reduced.

\section{Anodic and Cyclic Polarization}

The effect of the sinter-cooling rate and the simulated body fluids on the anodic polarization curves has been evaluated. In the literature, apart from many different media, different scanning rates are used ${ }^{24,30}$. One of the objectives of this work is to find the influence of these variables.

Figure 4 shows the potentiodynamic polarization curves of HNSS in a PBS solution for 10 and $50 \mathrm{mV} / \mathrm{min}$ scan rates and the two sintercooling rates. Because of porosity, the real current density cannot be correctly estimated. It is not possible to calculate such a real current density because the wet area inside the pores remains undetermined. Therefore, the current density is overestimated. The apparent surface was around $1.13 \mathrm{~cm}^{2}$ for every sample. Nevertheless, the interest of the work is to study HNSS on a comparative basis and, since its porosity is around $11-13 \%$, the influence of porosity will always be similar.

The curves in Figure 4 showed comparable shapes, though a more clear pitting potential for the furnace-cooled HNSS was observed. The lamellar constituent zones appear completely dissolved after the anodic polarization test. This indicates that they are the areas where pitting corrosion begins. The passive potential range was wider and the 
current density was lower for the water-cooled HNSS whatever the scan rate was. This passive range was unstable and around $10^{\circ} \mathrm{A} / \mathrm{m}^{2}$ for the furnace-cooled samples. The rest of the anodic branch corresponded to a continuous dissolution. The cathodic polarization branch was shifted to a lower potential when the sinter-cooling rate was decreased. The corrosion potential of the water-cooled HNSS was shifted towards more noble values. Finally, the anodic polarization branch, which corresponds to the metal dissolution and passive layer formation, became more stable for the water-cooled HNSS. These facts can be explained by considering the microstructural features. First, the chromium distribution of the furnace-cooled sample is heterogeneous due to the presence of the lamellar constituent and the precipitates. Second, nitrogen is completely dissolved in the water-cooled sample, which correspondingly enhances corrosion resistance. For the localized corrosion phenomena, the beneficial effect of nitrogen has been clearly confirmed as in others high nitrogen SS. ${ }^{11}$

When the potential scan rate decreased, a slight change in the anodic polarization of HNSS was observed (Figure 4). The corrosion potential shifted to a nobler potential and the anodic polarization branch became more stable. Furthermore, the current density decreased. Nevertheless, the morphology of the curves and the effect of the sinter-cooling rate remained the same. The furnace-cooled sample had a clear pitting potential and had a current density higher than for the water-cooled. Therefore, the water-cooling process is advisable for HNSS, irrespective of whether the scan rate is fast or slow.

The Ringer solution is another typical simulated body fluid richer in chloride ions that in general cause greater susceptibility to localized corrosion. The potentiodynamic polarization curves of HNSS in Ringer solution for slow and fast scan rates are shown in Figure 5. The influence of the sinter-cooling rate was not so evident as in the PBS solution, as far as corrosion potential is concerned. Nevertheless, the lowest current density was again observed for the water-cooled sample. The morphology and values of the anodic polarization scans were also similar for the two scan rates. The effect of the scan rate, though less, was similar to that for the PBS solution; the curves moved to lower current densities as the scan rate decreased.

On comparing the anodic scans for HNSS in both solutions, the corrosion potential was nobler for the Ringer solution than for the PBS solution, but the current density was similar or even higher in the anodic branch for the curves obtained in the Ringer solution.

As a result of the above the PBS solution and slow potential scan rate has proved to be the optimum for revealing differences between the two sinter-cooling rates. The effect of the sinter-cooling rate for the conventional $316 \mathrm{LN}$, is shown in Figure 6 . It can be seen that there was no beneficial effect for $316 \mathrm{LN}$ if a fast sinter-cooling rate was applied; on the contrary, its current density was even higher than for a furnacecooling process. This result had already been found for acid chloride corrosion behavior $^{35}$ and is repeated here for simulated body fluids. With the Ringer solution at a low scan rate, the effect of the sintercooling rate for $316 \mathrm{LN}$ was similar, but with an even higher anodic current density for the water-cooled sample (Figure 6). Therefore, contrary what is seen for HNSS, water-cooled $316 \mathrm{LN}$ showed higher current densities than furnace-cooled $316 \mathrm{LN}$ for both solutions. This could be explained by the presence of martensite in water-cooled $316 \mathrm{LN}$, as commented in the Microstructural Study section, and of course because of its absence in water-cooled HNSS. Accordingly, this implies a higher corrosion resistance of the water-cooled HNSS caused by the absence of secondary phases and the beneficial effect of nitrogen when it is in solid solution. For furnace-cooling, the differences between both materials were much less relevant. So it can be concluded that the HNSS has better anodic behavior than conventional $316 \mathrm{LN}$, once the fast sinter-cooling rate is provided.

Tafel analysis ${ }^{41}$ was done to examine the effect of the sinter-cooling rate on the corrosion resistance of HNSS. Table 4 shows the Tafel parameters for the PBS and Ringer solutions, under slow scan rate. The highest value of corrosion potential is observed for water-cooled HNSS in both solutions. In addition, the lowest current density was also found for this sample. The effect of the sinter-cooling rate on corrosion behavior is comparable for both solutions, although the highest current density values were registered for the Ringer solution which has a higher concentration of chlorides. Therefore, the results were in accordance with the previous paragraphs. The more homogeneous microstructure observed for water-cooled HNSS explains its better behavior.

Table 4 also shows the values of current density and corrosion potential for water- and furnace-cooled $316 \mathrm{LN}$. Again, the effect of the sinter-cooling rate was not exactly the same as that observed for HNSS. For $316 \mathrm{LN}$, as the cooling rate increased, the current density was not reduced as for HNSS, although the corrosion potential shifted to nobler values. The higher amount of lamellar constituent observed for furnace-cooled 316LN than for HNSS justifies the worse corrosion behavior of the former. For water-cooled samples, the HNSS showed a lower current density than the $316 \mathrm{LN}$ in both types of solution.

Figure 7 shows the cyclic polarization curves of HNSS for the two sinter-cooling rates recorded in PBS solution. This solution was chosen as a result of the previous discussion. It shows clearer differences between the furnace- and water-cooling processes. It is relevant to notice the high current densities of the furnace-cooled sample do not make possible to reach the cut density before the cut potential is reached. For furnace-cooled HNSS, a clear rupture of passive film was observed at $0.058 \mathrm{~V}_{\text {SCE}}$, and the reverse scan took an entirely different path when compared to the forward scan. A large hysteresis loop was found and a repassivation potential was registered near the open circuit potential. However, for water-cooled HNSS, the polarization curves showed a considerable improvement. The passive region extended to a higher anodic potential and no breakdown of the passive layer was observed, good resistance against localized corrosion has been confirmed for this sample. The hysteresis loop was considerably lower and the current density was also lower. This clearly indicates that the use of a high sinter-cooling rate is recommended, as was also shown by the anodic polarization measurements.

This novel material has shown better corrosion behavior than $316 \mathrm{LN}$ though its nickel content is lower. This suggests that HNSS can be used as a replacement material for the austenitic $316 \mathrm{~L}$. It can be stated that the main advantage of this new material is that nickel content is lowered and therefore the risk of allergic reactions is potentially reduced.

\section{Electrochemical Impedance Spectroscopy}

The impedance spectra can provide some insights on the modeling of the physicochemical processes of $316 \mathrm{LN}$ and HNSS during corrosion in PBS solution.

The Nyquist and the Bode plots obtained for the four samples at OCP are presented in Figure 8. The electrochemical impedance spectra of the Nyquist plots revealed a somewhat unfinished capacitive loop. This semicircle had a larger radius for HNSS than for $316 \mathrm{LN}$ and was largest when HNSS was water-cooled. Given that the radius of the semicircle is an indication of the resistance to the polarization of the material, it can 
be said that water-cooled HNSS is the one presenting greater resistance to the corrosion.

The impedance modulus of HNSS was more than one order of magnitude larger than $316 \mathrm{LN}$, which agrees in indicating its better corrosion behavior.

After several attempts to simulate the EIS results with different equivalent circuits used for PM materials, ${ }^{42-44}$ the quality of the fittings and the possibility in the low frequency region, of assigning a physical meaning to the circuit components led to manage the used to simulate the electrochemical behavior of PM SS, ${ }^{43}$ and wrought SS ${ }^{44}$ (Figure 9).

The suitability of this equivalent circuit to simulate the response of the porous samples can be seen in Figure 8 . The results of the fitting presented in Table 5. Chi-squared $\left(\chi^{2}\right)$ values were used to evaluate the quality of fitting. $\chi^{2}$ were of a magnitude order of $10^{-4}$ or lower indicating the suitability of the circuit. In the proposed model, shown in Figure 8, instead of capacitances two constant phase elements CPE (which represent a non-ideal capacitive response of the interface material-solution) were used. The depressed circle is an indication of this non-pure capacitive behavior. The surface heterogeneity resulting from dislocations, surface roughness, impurities and formation of porous layers could justify this behavior.

The impedance of a CPE element is defined as:

$$
Z_{C P E}=\frac{1}{C(j W)^{n}}
$$

where $C$ is a parameter numerically equal to the admittance at $\omega=1 \mathrm{rad}$ $s^{-1}, j$ is the imaginary unit, $\omega$ is the frequency, and $n$ is the phase shift.. When $n=1$ the CPE describe an ideal capacitor, when $n=0$ is an ideal resistor, when $n=-1$ is a pure inductance, when $n \approx 0.5$ is a finiteWarburg element accounting for diffusion of mobile charge. In practice, $\mathrm{n}$ is in the range of zero to one, and $\mathrm{C}$ can be approximately converted into a capacitance. ${ }^{45}$ The equivalent electrochemical circuit used describes the behavior of a passive layer on SS surface but this film is not perfect and presents some intrinsic defects. The depression in the Nyquist semicircle, the phase angle of capacitor different from $-90^{\circ}$ and the values of $\mathrm{n}$ shown in Table 5 are an indication of this. This suggest that some inhomogeneities are at the microscopic level at the metal-electrolyte interface (such as surface roughness, adsorbed species or other distributed properties). Therefore, $\mathrm{C}$ is not a true capacitance and its units are not $\mathrm{F} / \mathrm{cm}^{2}$.

The process is characterized by two time constants, as seen in Figures

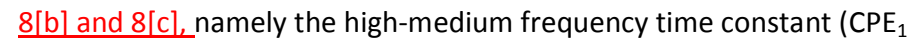
$-R_{1}$ ) related with the redox reaction on the material surface and the low-frequency time constant $\left(\mathrm{CPE}_{2}-\mathrm{R}_{2}\right)$ related to charge transfer process. $R_{s}$ is the resistance that appears at very high frequency related to ohmic resistance of the solution.

The first time constant $C P E_{1}$ is represented by the capacitance of the passive film in pore-free areas-and. The $R_{1}$ is the resistance of porous exide-values are too low to correspond to a stable passive oxide layer impregnated, but could be related with electrolytethe resistance of the redox transformation of the corrosion products that occurs on the surface of the oxide layer, as it has been observed in wrought $\mathrm{Ss}^{46}$ and in PM SS ${ }^{43}$. The defects on the passive layer may be a pathway to the penetration of the electrolyte. The existence of these pores promotes the appearance of the second electrical constant, which may indicate that the steel is submitted to a rapid corrosion due to the formation of a non-protective layer. The physical meaning of the second time constant is the response of the substrate on the base of the passive layer defects. $C P E_{2}$ and $\mathrm{R}_{2}$ can be related with charge-transfer process through the porous layer. The existence of these pores promotes the appearance of double-layer capacitance $\left(\mathrm{CPE}_{2}\right)$ and the charge-transfer resistance $\left(R_{2}\right)$.

Table 5 shows that the resistance of the solution $\left(R_{s}\right)$ remains almost constant for all tests. The resistances of the porous passive oxide layer $\left(R_{1}\right)$ are very low, typical of PM materials and they slightly depends on the material and cooling process. The values of $R_{1}$ for HNSS are slightly higher than for $316 \mathrm{LN}$. It is worth noting that the $R_{1}$ values are always meaningfully lower than $R_{2}$. For $R_{2}$ (the corrosion resistance of $S S$ ) the effect of the composition and the cooling rate are more significant. This could be related to a higher corrosion resistance for HNSS, due the beneficial effect of the nitrogen. Wan et al., ${ }^{47}$ for SS obtained by vacuum induction molding, had a higher transfer resistance with increased nitrogen content. This effect is especially important when nitrogen is in a solid solution, so the water-cooled HNSS showed the maximum $R_{2}$ value. As already commented, the sum of $R_{1}$ and $R_{2}$ is defined as the polarization resistance and is related to the corrosion resistance. It clearly decreasesincreases for water-cooled HNSS.

It can also be observed in Table 5 that the $\mathrm{CPE}_{1}-\mathrm{C}$ values are lower than the $C P E_{2}-C$, the differences are more significant for $316 \mathrm{LN}$. The $C P E_{2}-C$ values could seem high to correspond to a charge transfer process. This can be due to the fact that the measured capacitance values are divided by the apparent surface area instead of the real area; pores make that the real surface exposed to electrolyte is higher than that measured. This has already observed for others PM materials ${ }^{43,4648}$. Water-cooled $316 \mathrm{LN}$ sample showed the highest $C P E_{1}-C$ and lowest $R_{1}$ values. Thus, an increase of the $\mathrm{CPE}_{1}-\mathrm{C}$ and a reduction of the resistance would indicate the formation of a more defective oxide layer. The lowest $\mathrm{CPE}_{2}-\mathrm{C}$ values are obtained for HNSS samples indicating that nitrogen content increases the corrosion resistance.

The values of the $\mathrm{CPE}_{1}-\mathrm{n}$ coefficient vary between 0.60 and 0.78 , lower than 1 due to the presence of heterogeneities of the interface. Minor values have been found for $n$ coefficients corresponding to the $C P E_{2}$, near 0.5 , and are lower for $316 \mathrm{LN}$ samples than for HNSS samples. Low values for $n$ coefficients could be related with the diffusion processes through a passive layer with a large number of defects. This demonstrates that the metal dissolution of the samples is under mixed control, as usually occurs for austenitic SS in PBS solutions. ${ }^{4849}$

Table 6 shows there is a good correlation between the corrosion current density ( $i_{\text {corr }}$ ) obtained from the anodic polarization curves and the EIS measurements for the studied samples at OCP. The $i_{\text {corr }}$ values have been calculated following the Stern-Geary equation, ${ }^{4950}$ using $R_{1}+R_{2}$ as the polarization resistance $\left(R_{\text {pol }}\right)$ of the equation (2). The corrosion current density is defined as:

$$
\begin{aligned}
& i_{\text {corr }}=\frac{\mathrm{B}}{R_{\text {Pol }}} \\
& B=\frac{\beta_{a} \beta_{c}}{2.3\left(\beta_{a}+\beta_{c}\right)}
\end{aligned}
$$

where $\beta_{\mathrm{a}}$ and $\beta_{\mathrm{c}}$ are anodic and cathodic Tafel slopes.

As can be seen, $\mathrm{i}_{\text {corr }}$ evaluated from EIS measurements was, in general, slightly lower than $i_{\text {corr }}$ evaluated from the polarization curves. These small differences can be related to the different exposure time to the solution. The anodic polarization curves were measured after $5 \mathrm{~min}$, while the EIS spectra were measured after $30 \mathrm{~min}$. This could indicate that $i_{\text {corr }}$ decreased with the exposure time in the dissolution. In future work, the effect of exposure time will be investigated. 


\section{CONCLUSIONS}

A novel low-nickel austenitic powder metallurgy stainless steel has been studied. The objective of the work has been to investigate its electrochemical behavior in two typical simulated body fluids (PBS and Ringer solution). Results have been compared with a conventional austenitic powder metallurgy stainless steel.

* Two sinter-cooling rates have been set. One has been the typical slow cooling from sintering temperature; the other has been a very fast cooling obtained by quenching in water from sintering temperature. The water-cooling process has shown an austenitic microstructure, while for furnace-cooling, the presence of austenite and some precipitates, and especially the presence of a lamellar constituent, has been observed. In terms of possible corrosion behavior, the water-cooling process is recommended.

* Comparing corrosion behavior for the PBS and Ringer solutions, the former has been shown to discriminate more easily between the two sinter-cooling rates. The anodic polarization measurements have confirmed this matter. In addition, it is advisable to use a slow scan rate, since differences are also shown more clearly.

* The electrochemical behavior in the PBS and Ringer solutions under potentiodynamic techniques has also been compared with $316 \mathrm{LN}$, showing that this novel material reveals higher corrosion resistance under both sinter-cooling rates being fast sinter-cooling the recommended process. This novel material shows better performance as $316 \mathrm{~L}$ without Mo due to improved homogeneous structure.

* The value of the polarization resistance obtained from EIS measurements offers data about the protective passive layers that depend on the composition of the steel and the cooling rate. Corrosion current density obtained by anodic polarization curves and by EIS measurements are in agreement.

\section{ACKNOWLEDGEMENT}

The authors wish to thank Höganäs $A B$ (Denis Oshchepkov) for supplying of the metallic powders.

\section{References}

1. S.Virtanen, I. Milosev, E. Gomez-Barrena, R. Trebse, J. Salo, Y.T. Konttinen, Acta Biomater. 4 (2008): p. 468.

2. P.H. Kuck, "Nickel, Mineral Commodity Summaries 2009," U.S. Geological Survey, January 2009, p. 110.

3. L. Reclaru, R. Ziegenhagen, P.Y. Eschker, A. Blatter, J. Lemaître, Acta Biomater. 2 (2006): p. 433.

4. R. Franks, W.O. Binder, J. Thompson, Trans. SME 47 (1995): p. 231.

5. P.C. Pistorius, M. du Toit, "Low-Nickel Austenitic Stainless Steels: Metallurgical Constraints," 12th Int. Ferroalloys Congress, held June 6-9, 2010 (Helsinki, Finland: Outotec Oyj, 2010), p. 911.

6. J. Menzel, W. Krschner, G. Stein, ISIJ Int. 36 (1996): p. 893.

7. M. Sumita, T. Hanava, S.H. Teoh, Mat. Sci. Eng. C 24 (2004): p. 753.

8. M. Talha, C.K. Behera, O.P. Sinha, Mat. Sci. Eng. C 33 (2013): p. 3563.

9. A.J. Sedriks, Corrosion of Stainless Steels, 2nd ed. (New York, NY: John Wiley \& Sons, 1996).

10. H. Hännimen, J. Romu, R. llola, J. Tervo, A. Laitinen, J. Mater. Process. Tech. 117 (2001): p. 424.

11. K. Yang, Y. Ren, P. Wan, Sci. China Tech. Sci. 55 (2012): p. 329. 12. P. Wang, Y. Ren, B. Zhang, K. Yang, Mater. Sci. Eng. C 32 (2012): p.
510.

13. M. Metikoš-Hukovic, R.Babic, Z. Grubac, Z.Petrovic, N. Lajci, Corros. Sci. 53 (2011): p. 2176.

14. J.W. Simmons, Mater. Sci. Eng. A 207 (1996): p. 159.

15. J.W. Simmons, W.E. Kemp, J.S. Sunning, JOM 48, 4 (1996): p. 20.

16. N. Chawla, X. Deng, Mater. Sci. Eng. A 390 (2005): p. 98.

17. S. Fátima, V. Guido, L.Y. Cho, C. Pacheco, K. Regina, Mater. Res. 14 (2011): p. 208.

18. C. Garcia, F. Martin, P. de Tiedra, L. García Cambronero, Corros. Sci. 49 (2007): p. 1718.

19. C. Garcia, F. Martin, P. de Tiedra, Y. Blanco, J.M. Ruíz-Roman, M. Aparicio, Corros. Sci. 50 (2008): p. 687.

20. C. Garcia, F. Martin, Y. Blanco, Corros. Sci. 61 (2012): p. 45.

21. Z. Xu, C. Jia, C. Kuang, K. Chu, X. Qu, J. Alloy. Compd. 484 (2009): p. 924.

22. D.W. Cui, X.H. Qu, P. Guo, K-Li, Powder Metall. 53 (2010): p. 91.

23. D.W. Cui, J. Jiang, G. Cao, E. Xiao, X. Qu, J. Univ. Sci. Technol. B. 15 (2008): p. 150.

24. A. Dudek, R. Wlodarczyk, Mater. Sci. Eng. C 33 (2013): p. 434.

25. E. Salahinejad, R. Amini, M.J. Hadianfard, Powder Technol. 215-216 (2012): p. 247.

26. E. Salahinejad, M.J. Hadianfard, M. Ghaffari, R. Amini, S. Bagheri Mashhadi, A.K. Okyay, Adv. Powder Technol. 24 (2013): p. 605.

27. C. Suryanarayana, Prog. Mater. Sci. 46 (2001): p. 1.

28. A. Kocijan, I. Milosev, B. Pihlar, J. Mater. Sci. Mater. Med. 14 (2003): p. 69.

29. A. Kocijan, D. Merl, M. Jenko, Corros. Sci. 53 (2011): p. 776.

30. S. Karimi, T. Nickchi, A. Alfantazi, Corros. Sci. 53 (2011): p. 3262.

31. G. Burstein, C. Liu, Corros. Sci. 49 (2007): p. 4296.

32. A. Shahryari, S. Omanovic, J. A. Szpunar, Mater. Sci. Eng. C 28 (2008): p. 94.

33. Z. B. Saleh, A. Shahryari, S. Omanovic, Thin Solid Films 515 (2007): p. 4727.

34. D. Oshchepkov, "Nitrogen Containing, Low Nickel Sintered Stainless Steel," WIPO Patent Application WO/2011/045391, 2011.

35. C. Garcia, F. Martin, Y. Blanco, and G. Herranz, Corrosion 70 (2014): p. 1000-1007.

36. L.A. Dobrzanski, Z. Brytan, M.A. Grande, M. Rosso, E.J. Pallavicini, J. Mater. Process. Technol. 162-163 (2005): p. 286.

37. L.A. Dobrzanski, Z. Brytan, M.A. Grande, M. Rosso, J. Mater. Process. Technol. 191 (2007): p. 161.

38. M.R. Raza, F. Ahmad, M.A. Omar, R.M. German, J. Mater. Process. Technol. 212 (2012): p. 164.

39. ASTM G-5-87, "Standard Reference Test Method for Making Potentiostatic and Potentiodynamic Anodic Polarization Measurements" (West Conshohocken, PA: ASTM International, 1993), p. 1.

40. ASTM Standard G 61-86, "Standard Test Method for Conducting Cyclic Potentiodynamic Polarization Measurements for Localized Corrosion Susceptibility of Iron-Nickel, or Cobalt-Based Alloys" (West Conshohocken, PA: ASTM International, 2014), p. 1.

41. ASTM Standard G 59-91, "Standard Practice for Conducting Potentiodynamic Polarization Resistance Measurements" (West Conshohocken, PA: ASTM International, 2014), p. 1.

42. J. Ureña, E. Gordo, E. Ruiz-Navas, N. Vilaboa, L. Saldaña, A. JimenezMorales, Met. Powder Rep. 72 (2016): p. 1.

43. A. Bautista, A. González-Centeno, G. Blanco, S. Guzmán, Mater. Charact. 59 (2008): p. 32.

44. G. Blanco, A. Bautista, H. Takenouti, Cem. Concr. Compos. 28 (2006): p. 212.

45. C.H. Hsu, F. Mansfeld, Corrosion 57 (2001) p. 747.

46. L. Veleva, M.A. Alpuche-Aviles, M.K. Graves-Brook, D.O. Wipf, J. Electroanal. Chem. 537 (2002): p. 85A.V. . D.

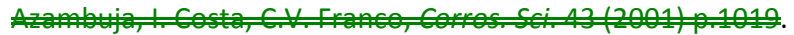

47. P. Wan, Y. Ren, B. Zhang, K.Yang, Mater. Sci. Eng. C 32 (2012): p. 
510.

48. A.V.C. Sobrl, W. Ristow, D.S. Azambuja, I. Costa, C.V. Franco, Corros. Sci. 43 (2001) p.101948.

49. S. Karimi, T. Nickchi, A. Alfantazi, Corros. Sci. 53(2011): p. 3262.

4950. M. Stearn, A. Geary, J. Electrochem. Soc. 104 (1957): p. 56.

\section{FIGURE CAPTIONS}

FIGURE 1. Optical micrographs of polished and etched HNSS: (a) furnace-cooled (Vilella's reagent), (b) furnace-cooled (oxalic etching), (c) water-cooled (oxalic etching). Austenite, lamellar constituent, and inter/transgranular precipitates are the identified microconstituents.

FIGURE 2. Backscattered electron detector SEM images of polished water-cooled (a) $316 \mathrm{LN}$ and (b) HNSS. Single phase with twined grains are identified as austenite.

FIGURE 3. X-ray diffractograms of water-cooled HNSS and 316LN. Austenite peaks identified as $\gamma$ and martensite marked as $\alpha^{\prime}$.

FIGURE 4. Potentiodynamic anodic polarization curves of furnace- and water-cooled HNSS in PBS solution and scan rates of $50 \mathrm{mV} / \mathrm{min}$ (fast) and $10 \mathrm{mV} / \mathrm{min}$ (slow).

FIGURE 5. Potentiodynamic anodic polarization curves of furnace- and water-cooled HNSS in Ringer solution and scan rates of $50 \mathrm{mV} / \mathrm{min}$ (fast) and $10 \mathrm{mV} / \mathrm{min}$ (slow).

FIGURE 6. Potentiodynamic anodic polarization curves of furnace- and water-cooled 316LN in PBS or Ringer solutions and a scan rate of 10 $\mathrm{mV} / \mathrm{min}$.

FIGURE 7. Cyclic potentiodynamic polarization curves of furnace- and water-cooled HNSS in PBS solution and a scan rate of $50 \mathrm{mV} / \mathrm{min}$.

FIGURE 8. Electrochemical impedance spectra in the form of (a) Nyquist plotand $(b, c)$ Bode plots of the four samples in PBS solution at open circuit potential. Equivalent circuit modelings are also included.

FIGURE 9. Equivalent electric circuit to interpret EIS measurements. 


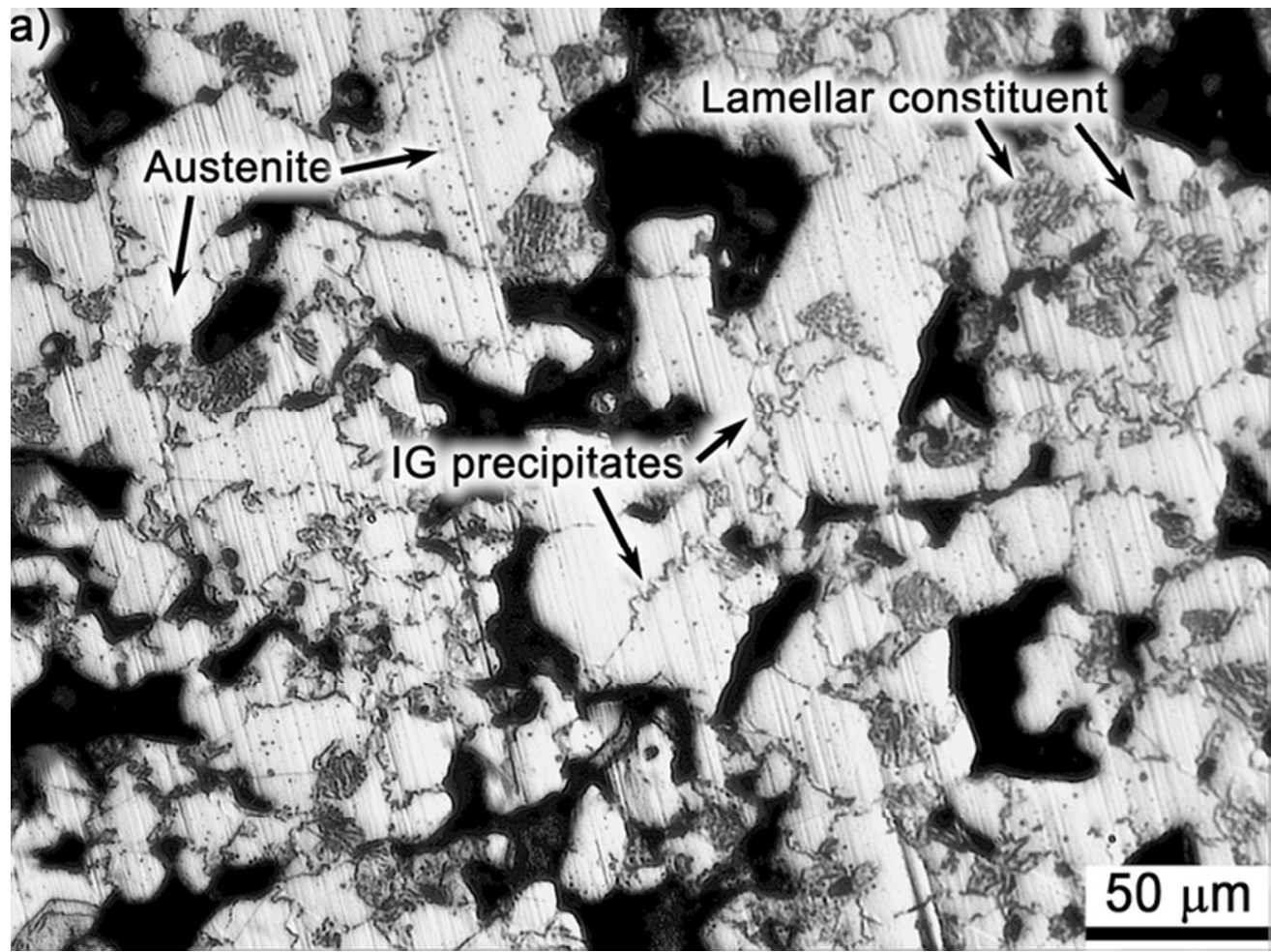

FIGURE 1. Optical micrographs of polished and etched HNSS: (a) furnace-cooled (Vilella's reagent), (b) furnace-cooled (oxalic etching), (c) water-cooled (oxalic etching). Austenite, lamellar constituent, and inter/transgranular precipitates are the identified microconstituents.

$62 \times 47 \mathrm{~mm}(300 \times 300 \mathrm{DPI})$ 


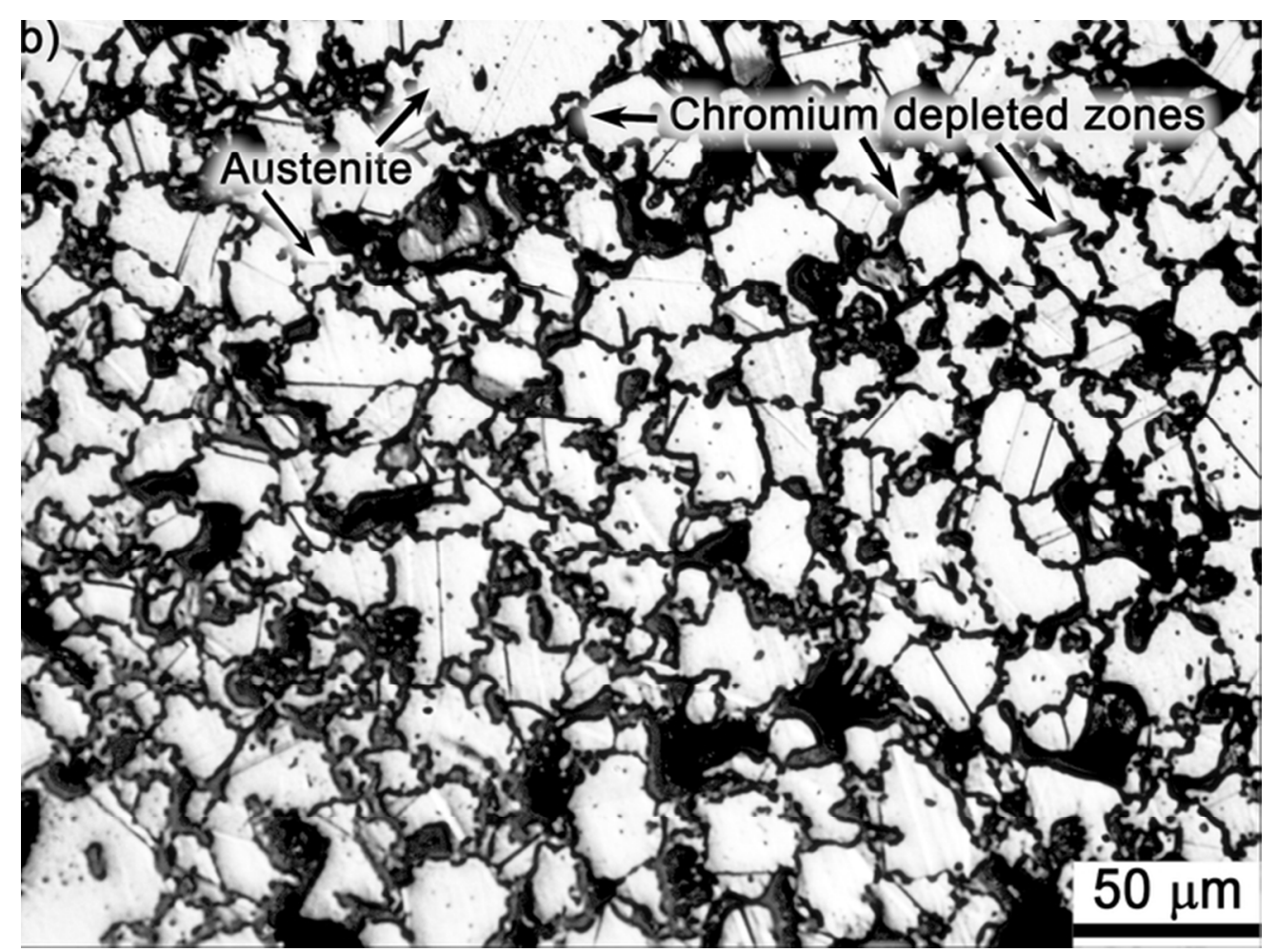

FIGURE 1. Optical micrographs of polished and etched HNSS: (a) furnace-cooled (Vilella's reagent), (b) furnace-cooled (oxalic etching), (c) water-cooled (oxalic etching). Austenite, lamellar constituent, and inter/transgranular precipitates are the identified microconstituents. 


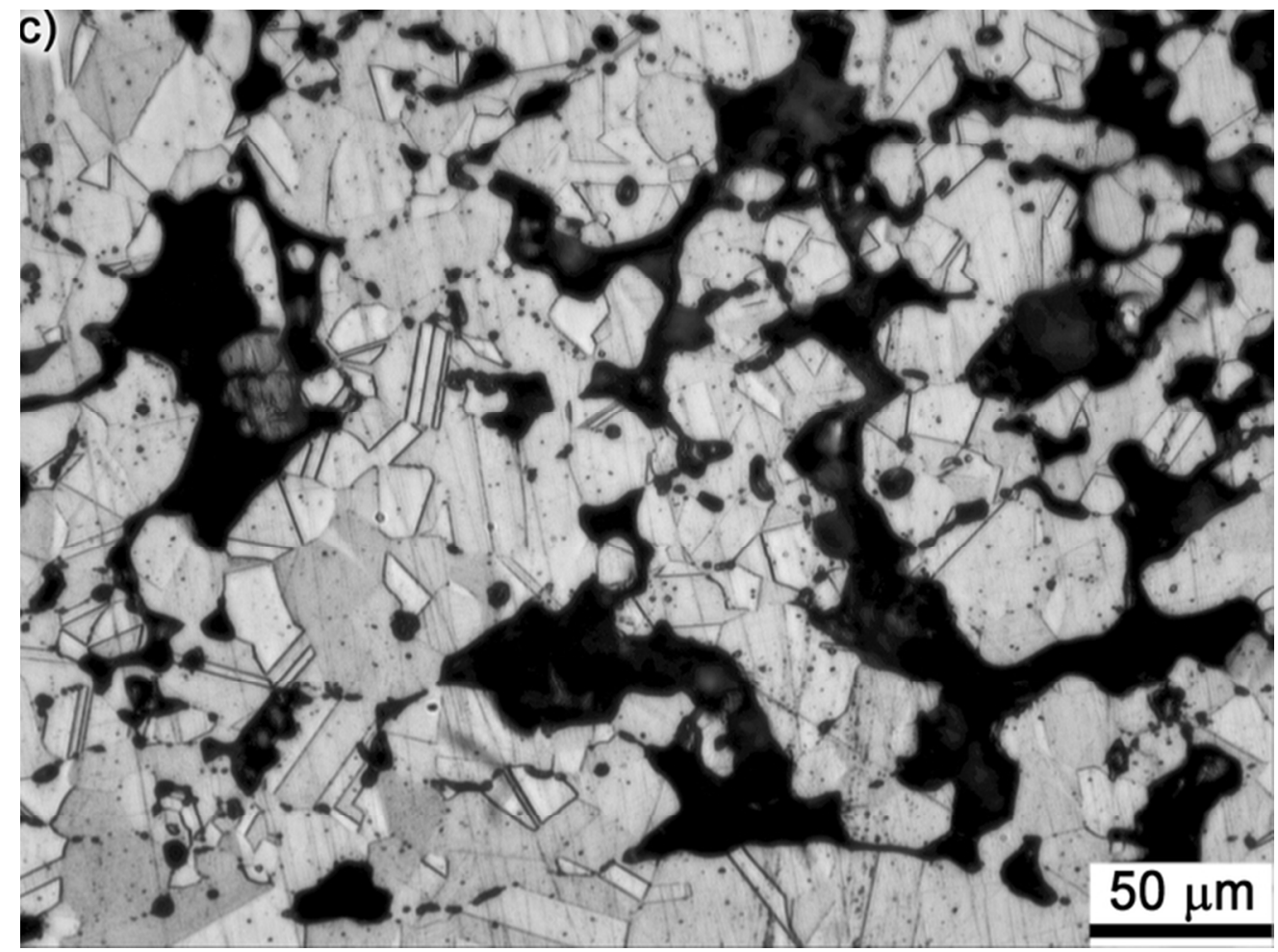

FIGURE 1. Optical micrographs of polished and etched HNSS: (a) furnace-cooled (Vilella's reagent), (b) furnace-cooled (oxalic etching), (c) water-cooled (oxalic etching). Austenite, lamellar constituent, and inter/transgranular precipitates are the identified microconstituents.

$62 \times 47 \mathrm{~mm}(300 \times 300$ DPI $)$ 


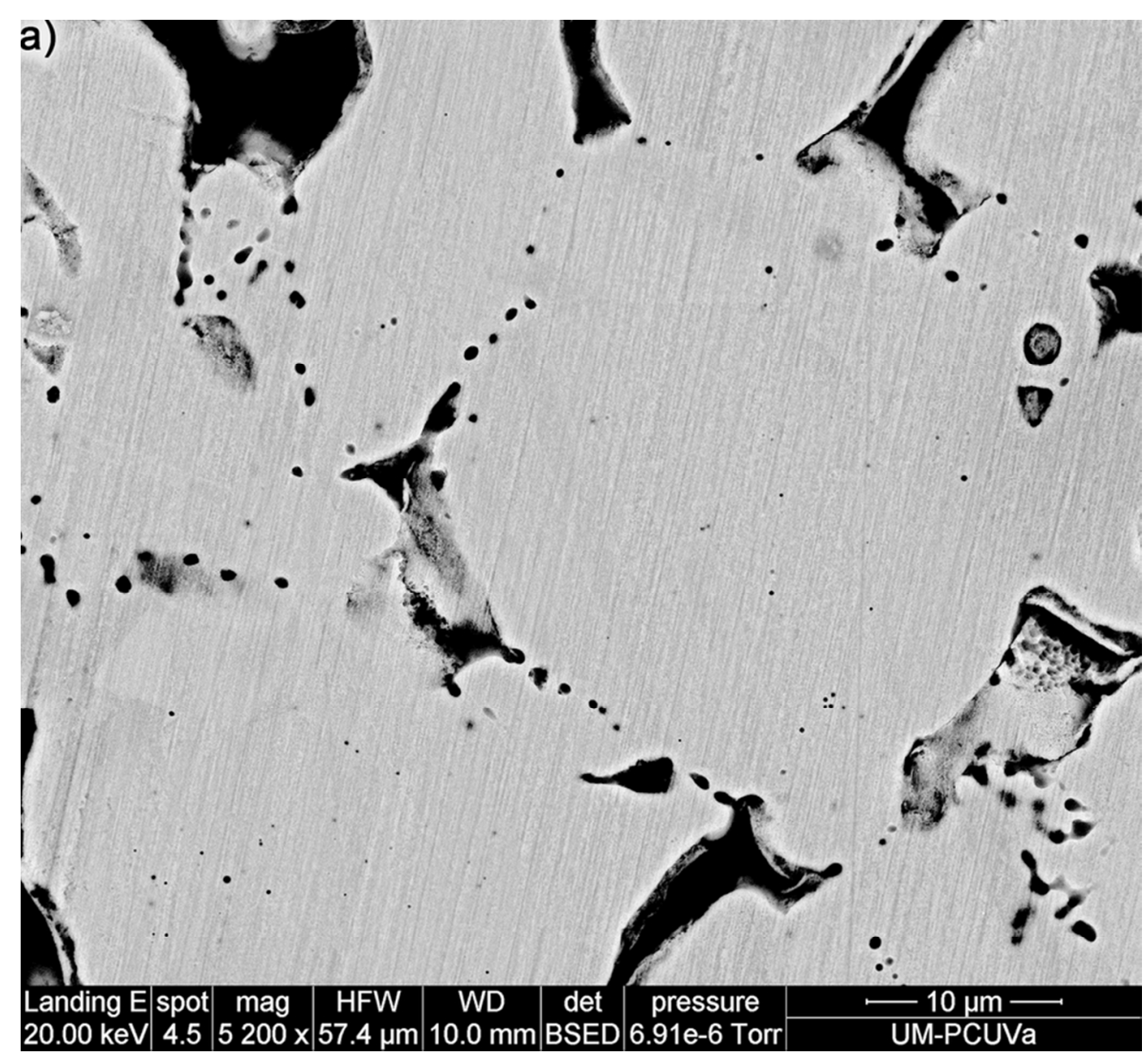

FIGURE 2. Backscattered electron detector SEM images of polished water-cooled (a) 316LN and (b) HNSS. Single phase with twined grains are identified as austenite. 


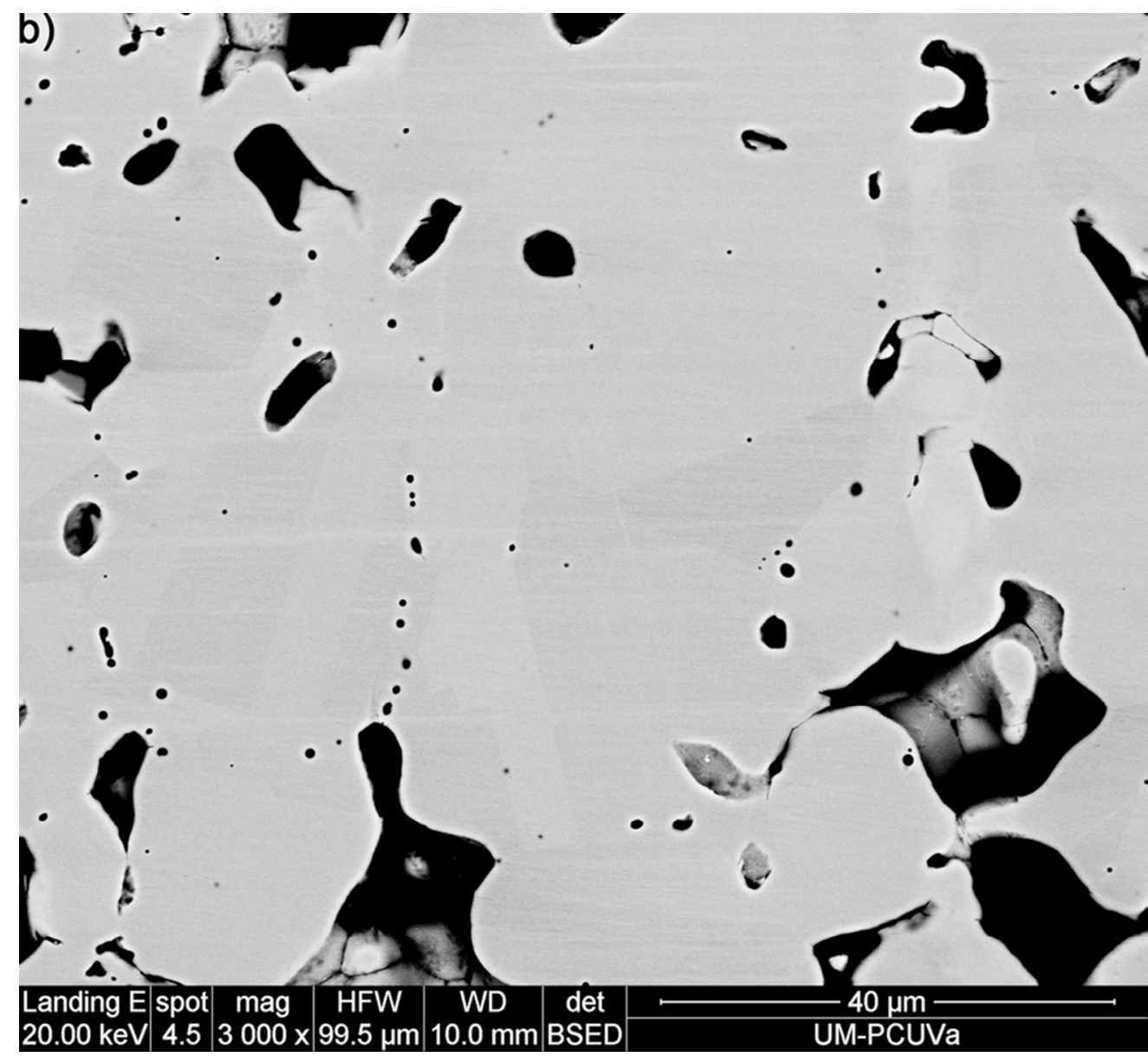

FIGURE 2. Backscattered electron detector SEM images of polished water-cooled (a) 316LN and (b) HNSS. Single phase with twined grains are identified as austenite.

$77 \times 71 \mathrm{~mm}(300 \times 300 \mathrm{DPI})$ 


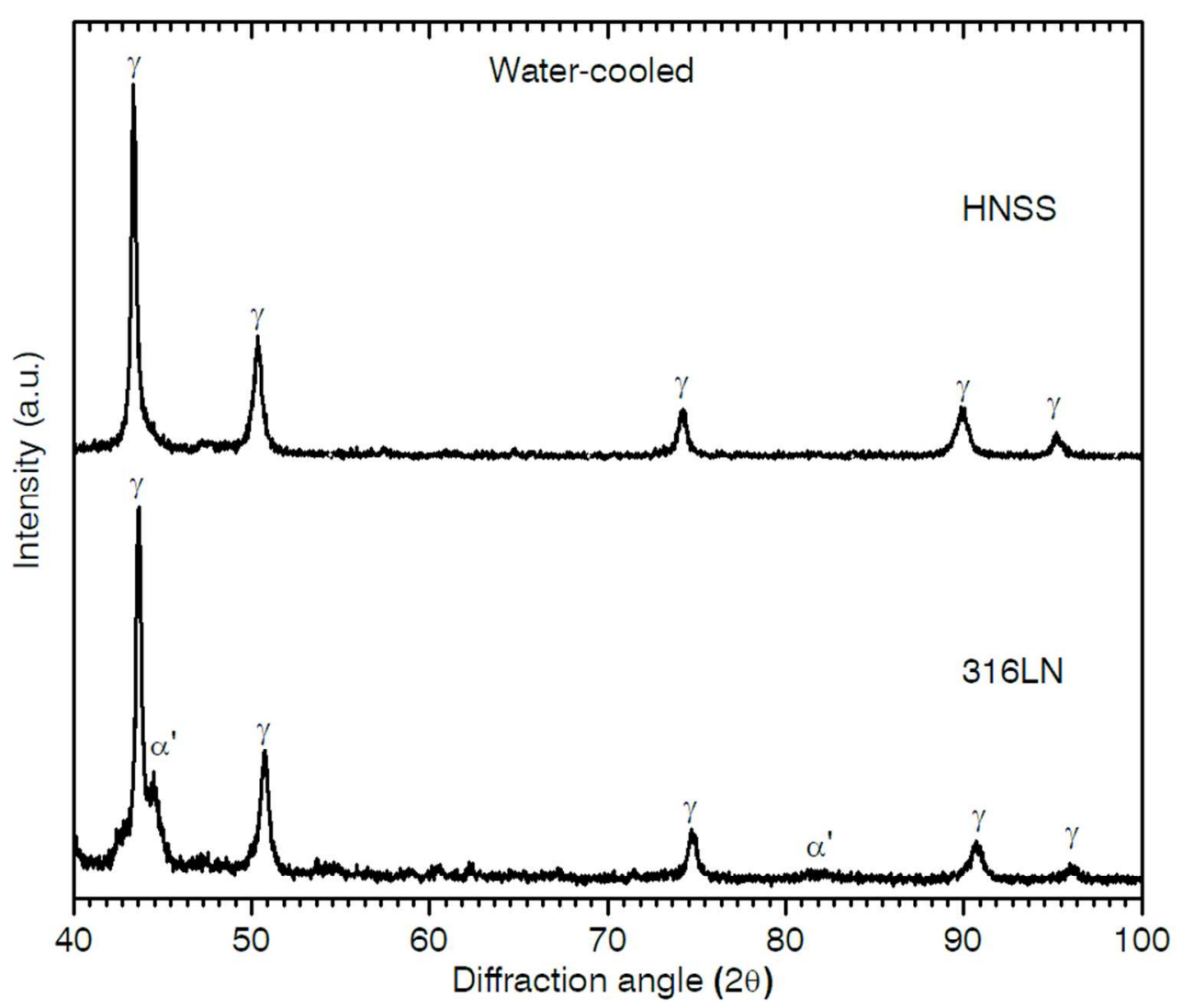

FIGURE 3. X-ray diffractograms of water-cooled HNSS and 316LN. Austenite peaks identified as $Y$ and martensite marked as $a^{\prime}$.

$83 \times 70 \mathrm{~mm}(300 \times 300$ DPI $)$ 


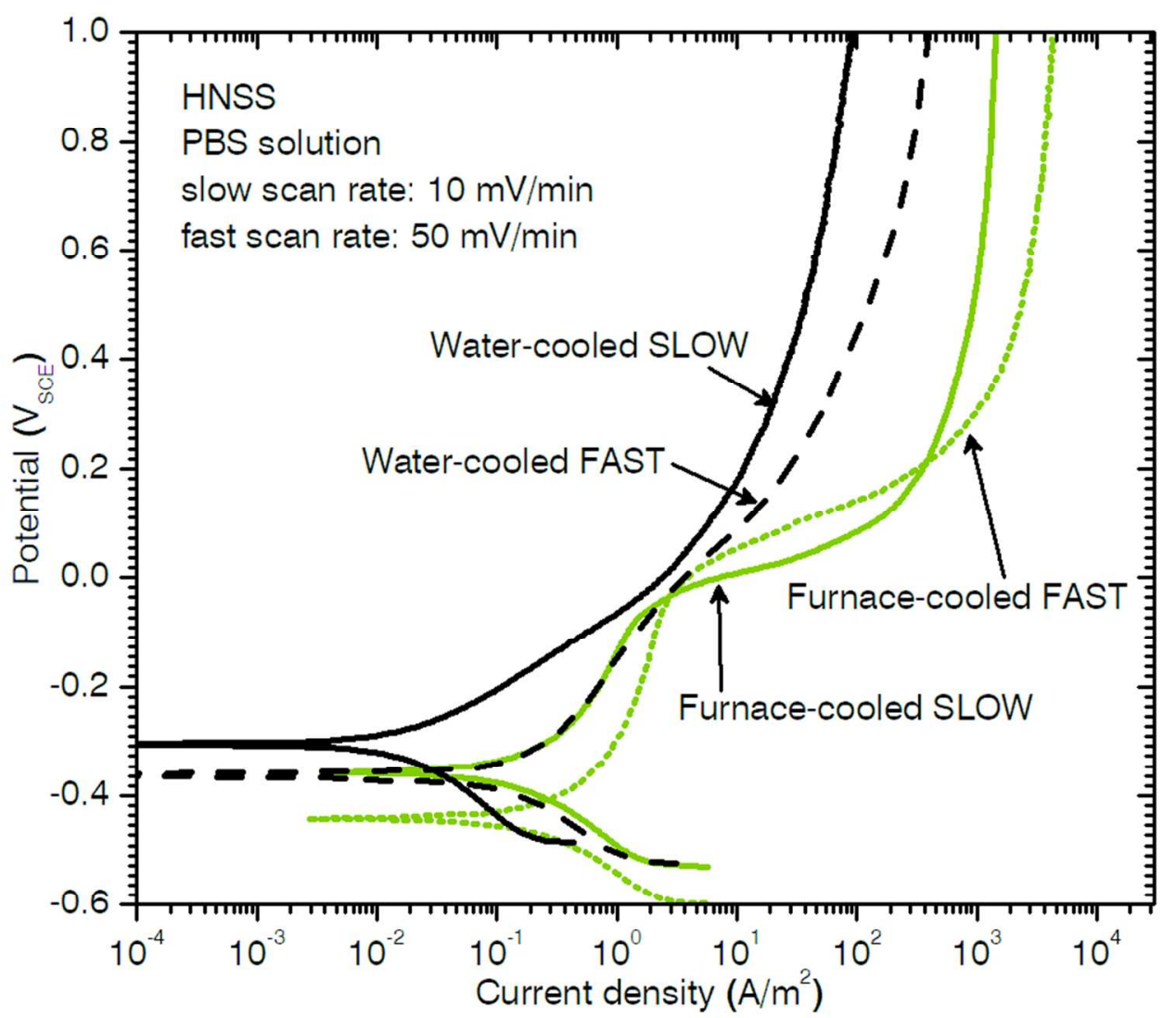

FIGURE 4. Potentiodynamic anodic polarization curves of furnace- and water-cooled HNSS in PBS solution and scan rates of $50 \mathrm{mV} / \mathrm{min}$ (fast) and $10 \mathrm{mV} / \mathrm{min}$ (slow).

$83 \times 70 \mathrm{~mm}(300 \times 300 \mathrm{DPI})$ 


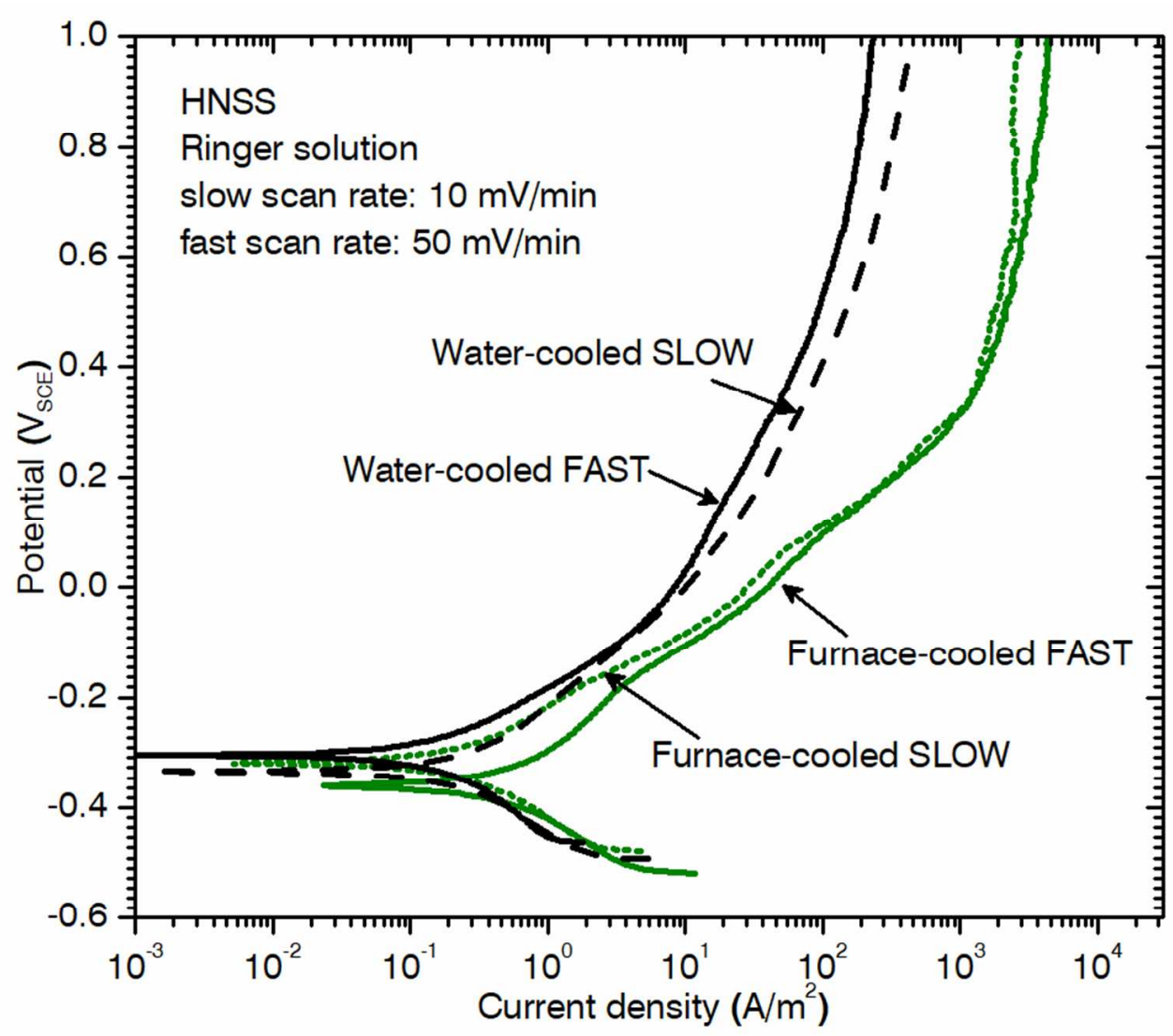

FIGURE 5. Potentiodynamic anodic polarization curves of furnace- and water-cooled HNSS in Ringer solution and scan rates of $50 \mathrm{mV} / \mathrm{min}$ (fast) and $10 \mathrm{mV} / \mathrm{min}$ (slow).

$83 \times 70 \mathrm{~mm}(300 \times 300 \mathrm{DPI})$ 


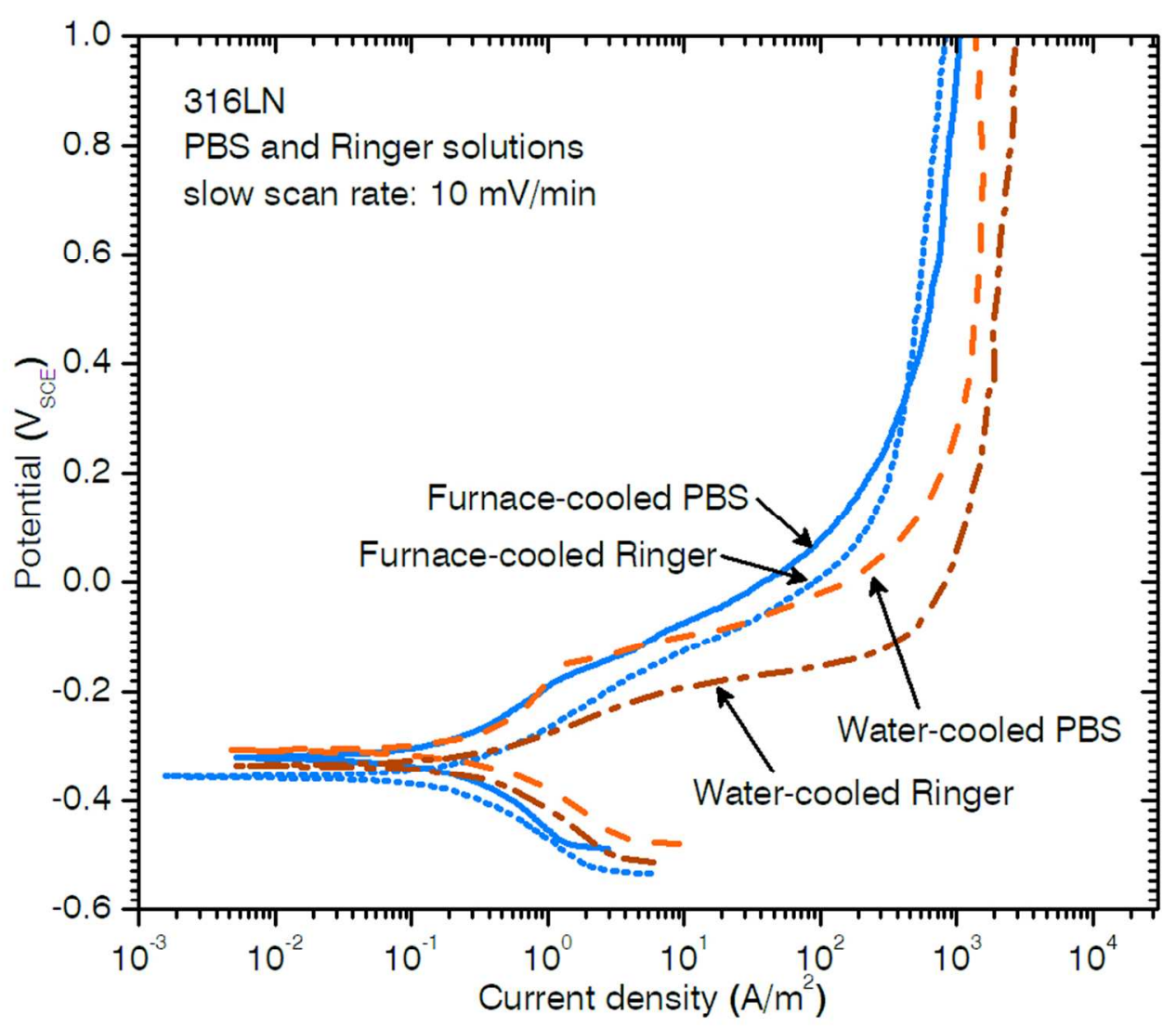

FIGURE 6. Potentiodynamic anodic polarization curves of furnace- and water-cooled 316LN in PBS or Ringer solutions and a scan rate of $10 \mathrm{mV} / \mathrm{min}$.

$83 \times 70 \mathrm{~mm}(300 \times 300$ DPI $)$ 


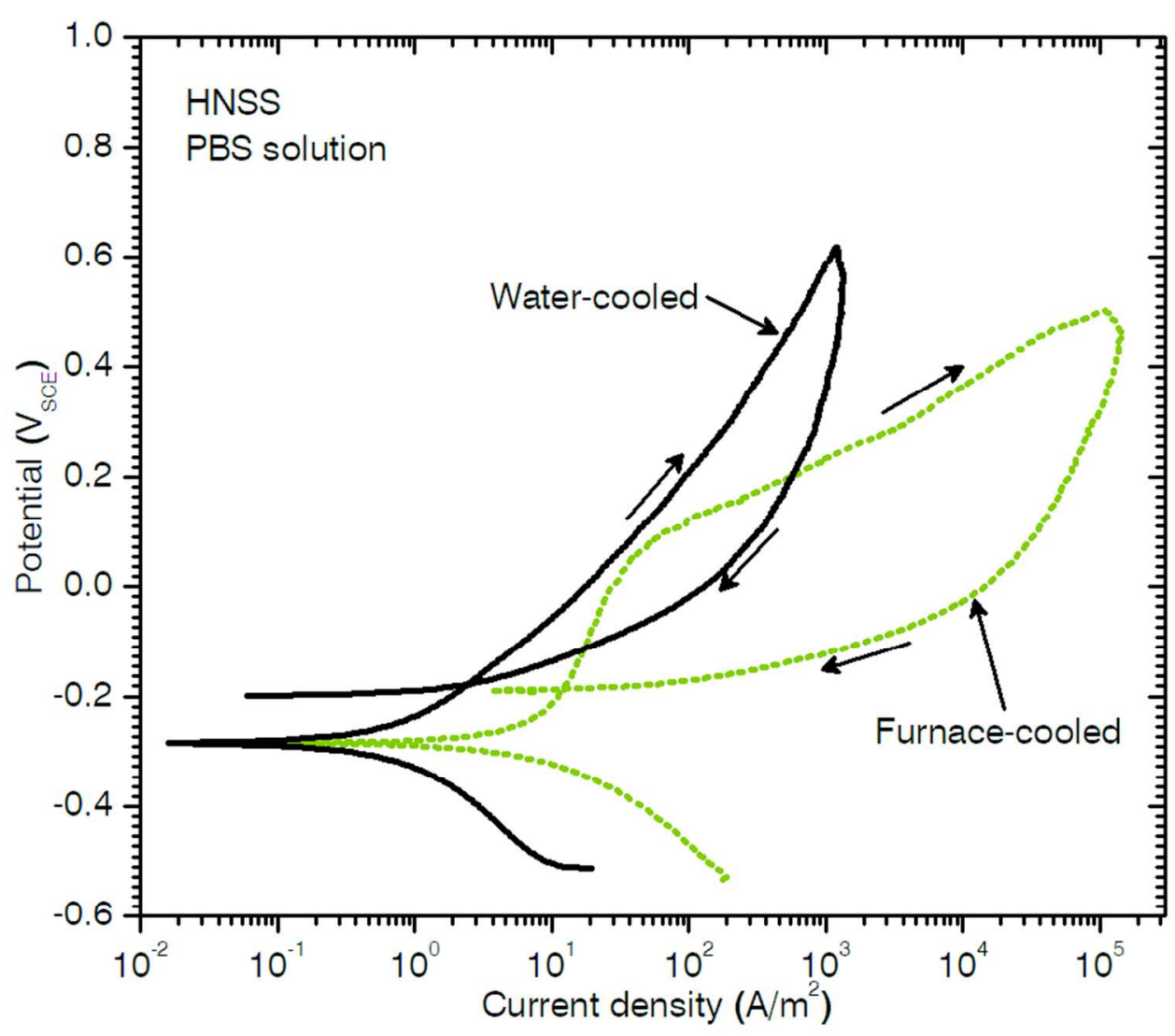

FIGURE 7. Cyclic potentiodynamic polarization curves of furnace- and water-cooled HNSS in PBS solution and a scan rate of $50 \mathrm{mV} / \mathrm{min}$.

$83 \times 70 \mathrm{~mm}(300 \times 300 \mathrm{DPI})$ 


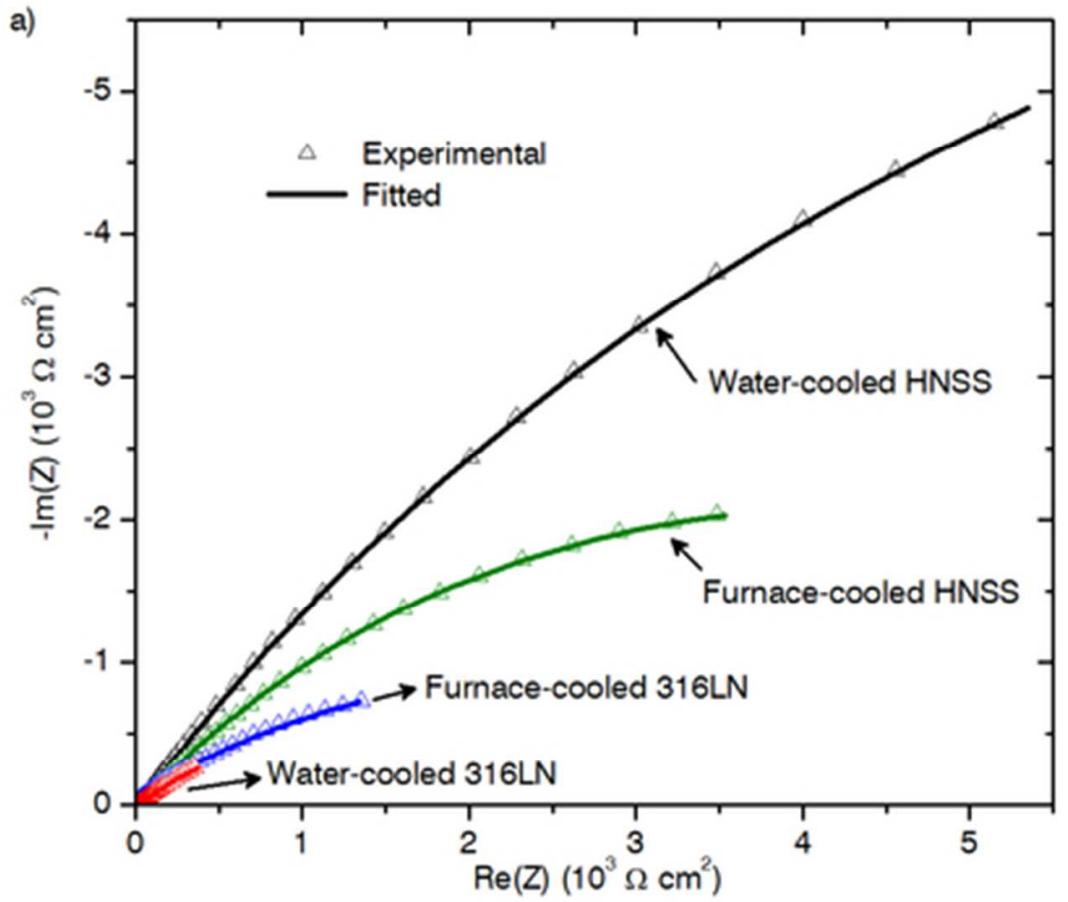

Electrochemical impedance spectra in the form of (a) Nyquist and $(b, c)$ Bode plots of the four samples in PBS solution at open circuit potential. Equivalent circuit modelings are also included. 


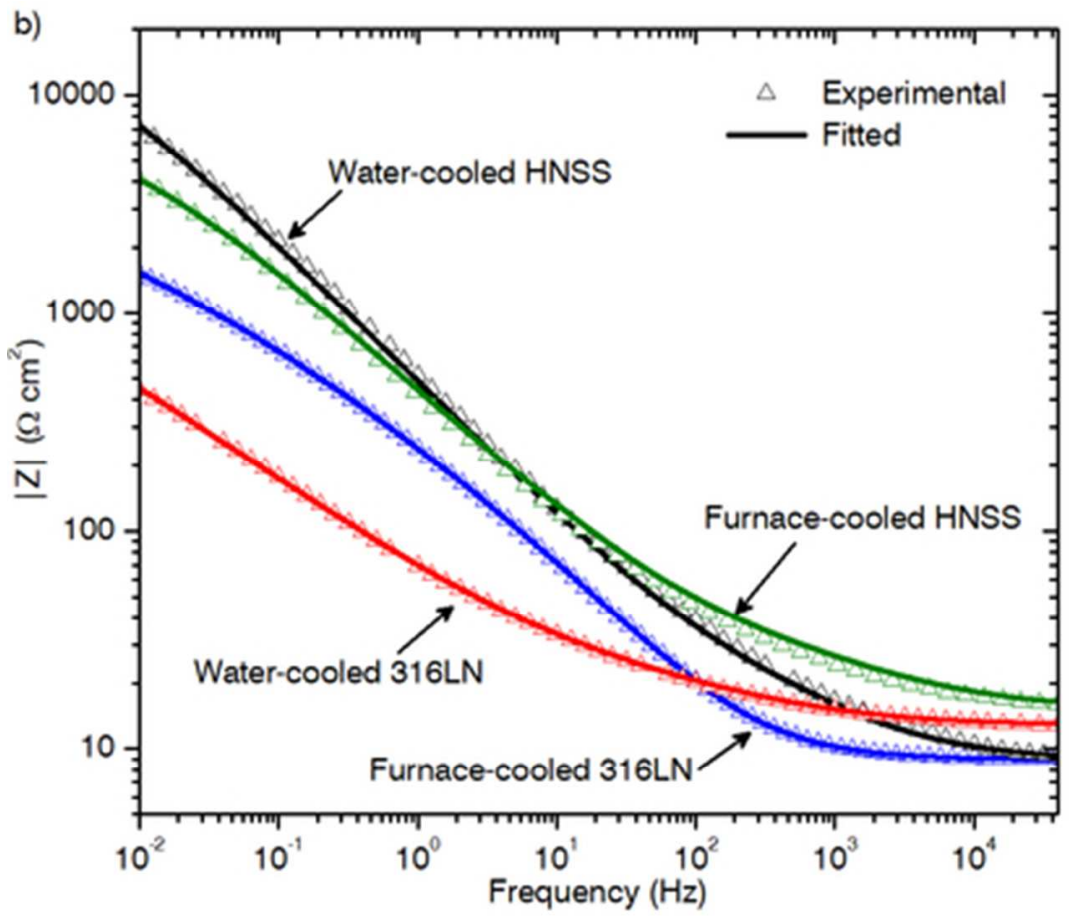

Electrochemical impedance spectra in the form of (a) Nyquist and (b,c) Bode plots of the four samples in PBS solution at open circuit potential. Equivalent circuit modelings are also included. 
c)

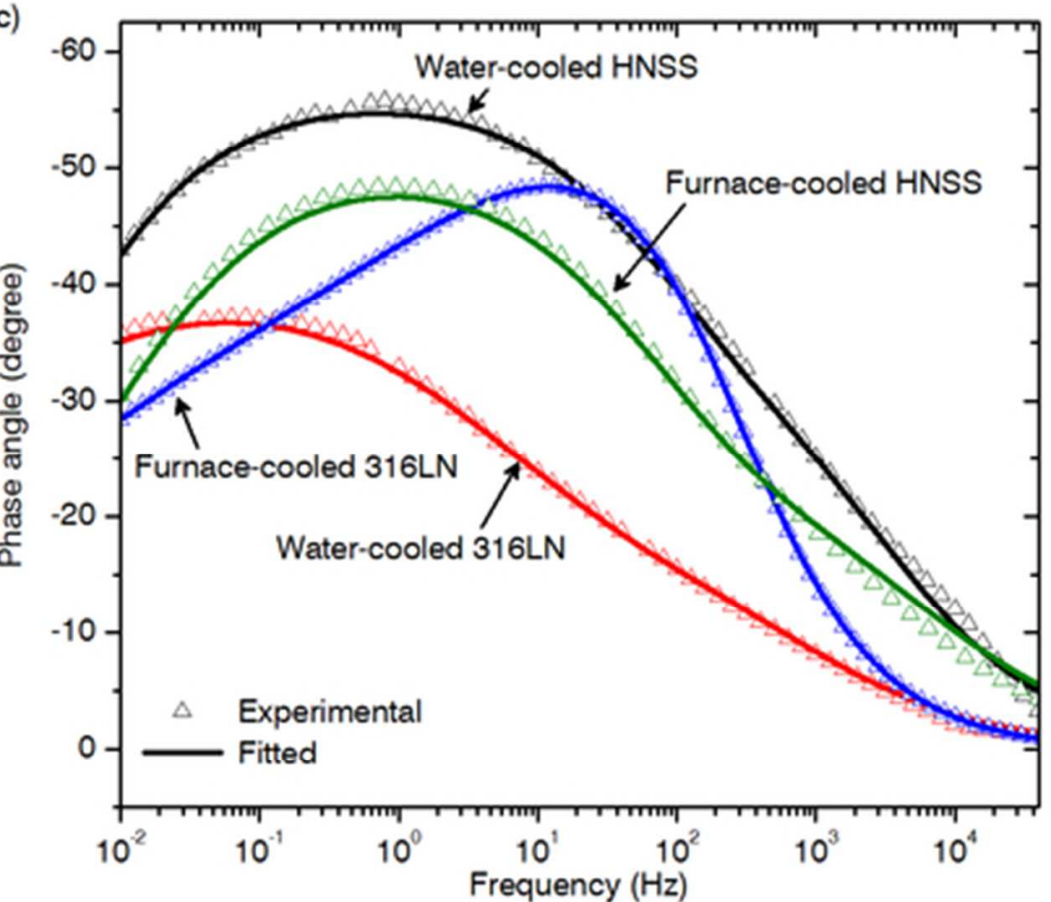

Electrochemical impedance spectra in the form of (a) Nyquist and $(b, c)$ Bode plots of the four samples in PBS solution at open circuit potential. Equivalent circuit modelings are also included. 
Page 21 of 27

CORROSION

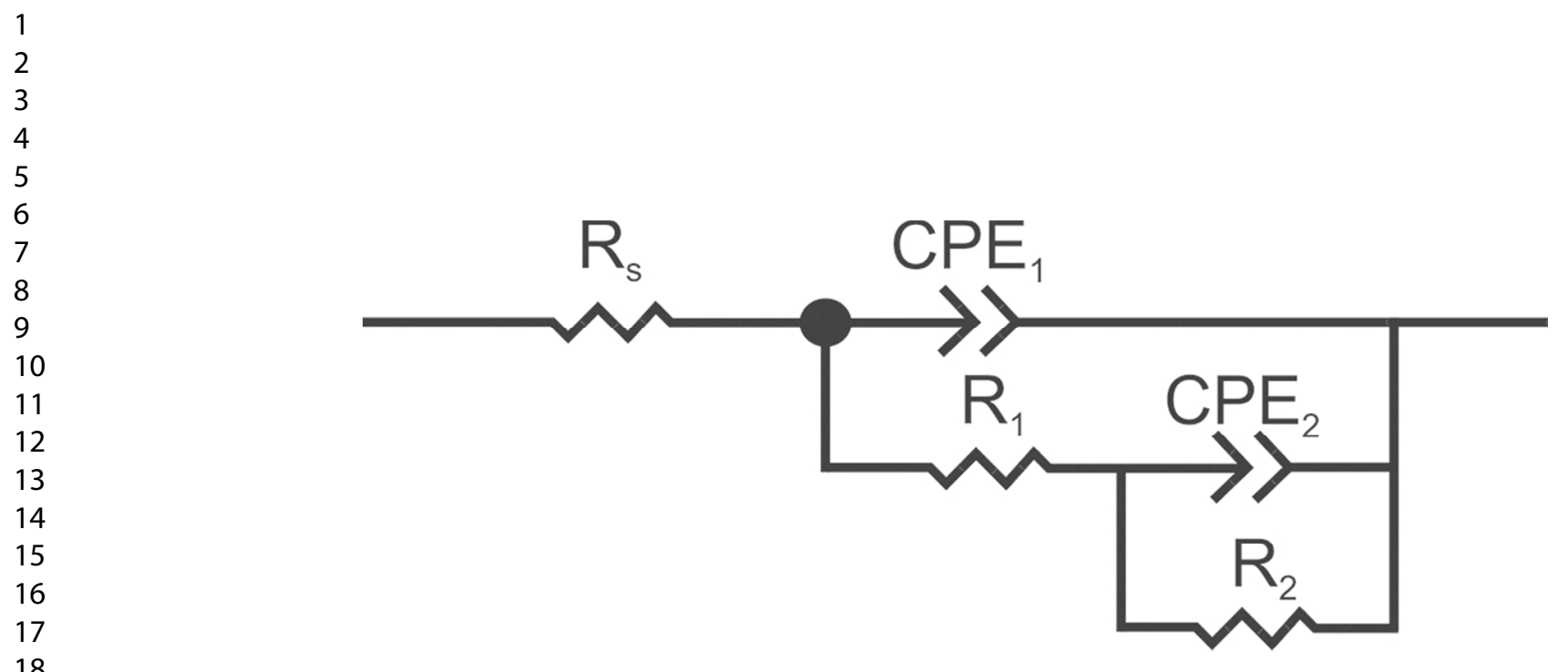

FIGURE 9. Equivalent electric circuit to interpret EIS measurements.

$$
83 \times 30 \mathrm{~mm}(300 \times 300 \text { DPI })
$$


TABLE 1

Chemical composition of HNSS and 316LN after sintering. Units in wt\%.

\begin{tabular}{llllllllllll}
\hline Sample & $\mathbf{C}$ & $\mathbf{S i}$ & $\mathbf{M n}$ & $\mathbf{C r}$ & $\mathbf{N i}$ & $\mathbf{M o}$ & $\mathbf{C u}$ & $\mathbf{S n}$ & $\mathbf{N}$ & $\mathbf{A l}$ & $\mathbf{F e}$ \\
\hline HNSS & 0.03 & 0.94 & 0.14 & 19.45 & 5.27 & 0.49 & 0.95 & 1.5 & 0.38 & 0.0081 & bal. \\
316LN & 0.021 & 0.87 & 0.20 & 16.1 & 13.55 & 2.24 & 0.02 & - & 0.35 & - & bal. \\
\hline
\end{tabular}

10

11

12

13

14

15

16

17

18

19

20

21

22

23

24

25

26

27

28

29

30

31

32

33

34

35

36

37

38

39

40

41

42

43

44

45

46

47

48

49

50

51

52

53

54

55

56

57

58

59

60 
1

2

3

4

5

6

7

8

9

10

11

12

13

14

15

16

17

18

19

20

21

22

23

24

25

26

27

28

29

30

31

32

33

34

35

36

37

38

39

40

41

42

43

44

45

46

47

48

49

50

51

52

53

54

55

56

57

58

59

60 57

TABLE 2

Green and sintering densities and porosity of HNSS and 316LN after furnace- and water-cooling processes.

\begin{tabular}{lllll}
\hline Sample & Sinter-cooling & $\begin{array}{l}\text { Green density } \\
\left(\mathrm{g} / \mathrm{cm}^{\mathbf{3}}\right)\end{array}$ & $\begin{array}{l}\text { Sintering density } \\
\left(\mathrm{g} / \mathrm{cm}^{\mathbf{3}}\right)\end{array}$ & $\begin{array}{l}\text { Porosity } \\
(\%)\end{array}$ \\
\hline HNSS & Furnace & 6.4 & 6.8 & 11.2 \\
& Water & & 7.0 & 11.0 \\
\multirow{3}{*}{$316 \mathrm{LN}$} & Furnace & 6.6 & 6.7 & 13.0 \\
& Water & & 7.2 & 11.2 \\
\hline
\end{tabular}

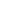

(1)

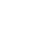

(1)

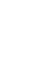

(1)

4

5

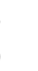

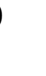
5 36 8 9 ( ( 4 ( (1)

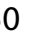
(a) (2)

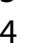
5 (n) 
1

2

3

4

5

6

7

8

9

10

11

12

13

14

15

16

17

18

19

20

21

22

23

24

25

26

27

28

29

30

31

32

33

34

35

36

37

38

39

40

41

42

43

44

45

46

47

48

49

50

51

52

53

54

55

56

57

58

59

60

TABLE 3

EDS results for grains of water-cooled HNSS and 316LN. Nitrogen and carbon content were not calculated due to the low resolution of EDS for light elements. Units in wt\%.

\begin{tabular}{lllllll}
\hline Sample & $\mathbf{S i}$ & $\mathbf{C r}$ & $\mathbf{N i}$ & $\mathrm{Mo}$ & $\mathrm{Cu}$ & $\mathrm{Sn}$ \\
\hline HNSS & 0.7 & 18.7 & 4.1 & 0.8 & 1.2 & 2.0 \\
316LN & 0.6 & 16.8 & 12.0 & 2.4 & - & - \\
\hline
\end{tabular}


TABLE 4

Corrosion potential and corrosion current density calculated by Tafel of HNSS and 316LN after furnace-and water-cooling processes and the two test solutions under slow scan rate $(10 \mathrm{mV} / \mathrm{min})$.

\begin{tabular}{lllll}
\hline Sample & $\begin{array}{l}\text { Test } \\
\text { solution }\end{array}$ & $\begin{array}{l}\text { Sinter- } \\
\text { cooling }\end{array}$ & $\begin{array}{l}\text { Corrosion } \\
\text { potential } \\
\left(\mathbf{V}_{\text {SCE }}\right)\end{array}$ & $\begin{array}{l}\text { Corrosion } \\
\text { current density } \\
\left(\mathbf{A} / \mathbf{m}^{2}\right)\end{array}$ \\
\hline HNSS & PBS & Furnace & $-0.357 \pm 0.003$ & $0.070 \pm 0.004$ \\
& & Water & $-0.280 \pm 0.005$ & $0.021 \pm 0.003$ \\
& \multirow{2}{*}{ Ringer } & Furnace & $-0.318 \pm 0.006$ & $0.088 \pm 0.007$ \\
& & Water & $-0.305 \pm 0.003$ & $0.039 \pm 0.001$ \\
$316 \mathrm{LN}$ & \multirow{2}{*}{ PBS } & Furnace & $-0.320 \pm 0.008$ & $0.154 \pm 0.008$ \\
& \multirow{2}{*}{ Ringer } & Water & $-0.307 \pm 0.004$ & $0.242 \pm 0.010$ \\
& & Furnace & $-0.356 \pm 0.003$ & $0.132 \pm 0.004$ \\
& & Water & $-0.335 \pm 0.008$ & $0.266 \pm 0.010$ \\
\hline
\end{tabular}

14

15

16

17

18

19

20

21

22

23

24

25

26

27

28

29

30

31 
TABLE 5

EIS equivalent circuit parameters.

\begin{tabular}{|c|c|c|c|c|c|c|c|c|c|}
\hline Sample & $\begin{array}{l}\text { Sinter- } \\
\text { cooling }\end{array}$ & $\begin{array}{l}R_{s} \\
\left(\Omega \mathrm{cm}^{2}\right)\end{array}$ & $\begin{array}{l}\mathrm{CPE}_{1}-\mathrm{C} \\
\left(10^{-4} \mathrm{~s}^{\mathrm{n}} \Omega^{-1} \mathrm{~cm}^{-2}\right)\end{array}$ & $\mathrm{CPE}_{1}-\mathrm{n}$ & $\begin{array}{l}R_{1} \\
\left(\Omega \mathrm{cm}^{2}\right)\end{array}$ & $\begin{array}{l}R_{2} \\
\left(\Omega \mathrm{cm}^{2}\right)\end{array}$ & $\begin{array}{l}\mathrm{CPE}_{2}-\mathrm{C} \\
\left(10^{-4} \mathrm{~s}^{\mathrm{n}} \Omega^{-1} \mathrm{~cm}^{-2}\right)\end{array}$ & $\mathrm{CPE}_{2}-\mathrm{n}$ & $\begin{array}{l}\chi^{2} \\
\left(10^{-4}\right)\end{array}$ \\
\hline \multirow[t]{2}{*}{ HNSS } & water & 8.8 & 3.15 & 0.65 & 30.86 & 24163 & 3.30 & 0.62 & 0.53 \\
\hline & furnace & 15.0 & 3.36 & 0.58 & 31.00 & 8500 & 4.46 & 0.58 & 0.67 \\
\hline \multirow[t]{2}{*}{$316 \mathrm{LN}$} & furnace & 8.9 & 3.82 & 0.78 & 22.92 & 5875 & 14.4 & 0.39 & 0.76 \\
\hline & water & 12.8 & 15.40 & 0.59 & 12.72 & 2935 & 60.9 & 0.45 & 0.67 \\
\hline
\end{tabular}


1

2

3

4

5

6

7

8

9

10

11

12

13

14

15

16

17

18

19

20

21

22

23

24

25

26

27

28

29

30

31

32

33

34

35

36

37

38

39

40

41

42

43

44

45

46

47

48

49

50

51

52

53

54

55

56

57

58

59

60

TABLE 6

Corrosion current density calculated from anodic polarization curves and from EIS measurements.

\begin{tabular}{llllll}
\hline Sample & $\begin{array}{l}\text { Sinter- } \\
\text { cooling }\end{array}$ & $\begin{array}{l}\mathbf{i}_{\text {corr }} \text { from } \\
\text { polarization } \\
\text { curves } \\
\left(\mathbf{A} / \mathbf{m}^{2}\right)\end{array}$ & $\boldsymbol{\beta}_{\mathrm{a}}$ & $\boldsymbol{\beta}_{\mathbf{c}}$ & $\begin{array}{l}\mathbf{i}_{\text {corr }} \text { from EIS } \\
\left(\mathbf{A} / \mathbf{m}^{2}\right)\end{array}$ \\
\hline HNSS & water & 0.021 & 115 & $\mathbf{( m V )}$ & \\
& furnace & 0.070 & 160 & 489 & 0.017 \\
$316 \mathrm{LN}$ & furnace & 0.154 & 203 & 305 & 0.091 \\
& water & 0.242 & 179 & 361 & 0.177 \\
\hline
\end{tabular}

